\title{
How do research intensive systems emerge in less developed areas? The case of mechatronics in the Italian southern region Apulia
}

\author{
Stefano Clò* and Massimo Florio \\ Department of Economics, \\ Management and Quantitative Methods, \\ University of Milan, \\ Conservatorio, 20122, Milan, Italy \\ Email: stefano.clo@unimi.it \\ Email: massimo.florio@unimi.it \\ *Corresponding author

\section{Julie Pellegrin and Emanuela Sirtori}

CSIL: Centre for Industrial Studies,

Corso Monforte, 15, 20122 Milan, Italy

Email: pellegrin@csilmilano.com

Email: sirtori@csilmilano.com

\begin{abstract}
Regional innovation systems (RISs) are increasingly emerging in less developed areas. Based on the case study of the mechatronic cluster in the Italian southern region, Apulia, this paper analyses how institutions have managed to promote the establishment of a RIS in disadvantaged areas. Through a longitudinal analysis over more than half a century, the Apulian case study shows that the creation of this RIS in less developed areas is the result of a dynamic process characterised by a multi-level governance, initially promoted by the central government through a top-down logic, and then integrated by action of local actors through a bottom-up approach. A key role is played by the regionalisation of innovation policies and by the strategic action of regional public institutions to promote the interaction among enterprises and universities. Our analysis highlights that several ingredients should simultaneously occur for a regional innovation policy to be effective. Any regional innovation strategy significantly lacking one of these core pre-conditions and ingredients is risky. Policy-makers should carefully study the opportunities and challenges arising from local contexts before embarking in ambitious place-based innovation strategies.
\end{abstract}

Keywords: regional innovation system; RIS; technological cluster; less developed area; mechatronics; Italy; regionalisation of innovation policy; case study.

Reference to this paper should be made as follows: Clò, S., Florio, M., Pellegrin, J. and Sirtori, E. (2018) 'How do research intensive systems emerge in less developed areas? The case of mechatronics in the Italian southern region Apulia', Int. J. Technological Learning, Innovation and Development, Vol. 10, No. 1, pp.1-36.

Biographical notes: Stefano Clò is an Assistant Professor at the University of Milan. His interests of research include public economics, energy and environmental economics, and economics of innovation. 
Massimo Florio is a Professor of Public Economics and Jean Monnet Chair 'Ad personam' of EU Industrial Policy at the University of Milan. He is acknowledged at European level as a top expert in the evaluation of EU policies, programmes and projects.

Julie Pellegrin is the Director of the Regional Development unit CSIL. She specialises in public policy analysis in the fields of regional development and innovation policies. She has gained considerable experience in managing complex evaluation and research studies on behalf of the European Commission, other European and international organisations, as well as national and regional authorities.

Emanuela Sirtori is an expert at the CSIL in development and evaluation studies. She gained relevant experience in cost-benefit analysis of infrastructural projects and evaluation of the impact of structural funds. She has participated in different evaluation studies on behalf of the European Parliament and of the European Commission.

\section{Introduction}

Enterprises with a coherent specialisation profile tend to cluster in specific areas, often centred on one or few large catalysing enterprises. The reduction of physical distance is associated with a reduction in the searching, transaction and transportation costs and facilitates interaction among firms, bringing to important synergies and external economies, such as technological spill over, labour market pooling, and economies of scope in the management of intermediate inputs (Krugman, 1991; Porter, 1998). Classic contributions to the understanding of industrial districts stress how clusters are likely to flourish in developed areas characterised by well-established economic, territorial and social conditions. The presence of well-functioning services and infrastructures; specialised labour force; reliable institutions; social capital, reciprocal trust, a cooperative and interdependent governance are deemed to be a pre-condition for the development of geographically concentrated and interconnected businesses (Becattini et al., 2009).

One could argue that the opportunity to exploit agglomeration economies becomes less relevant in the new high-tech economy, where the virtual distance disappears, communication costs drastically decrease, and where the main input for innovation is knowledge and human capital rather than row materials (Keeble and Wilkinson, 1999). Against this view, wide empirical evidence shows that research and innovation activities tend as well to physically and spatially agglomerate in defined geographical areas. Local or regional networks between public and private agents interacting in a specific territory which adapt, generate and extend knowledge and innovation have been defined in the literature as regional innovation systems (RISs) (Cooke et al., 1997). While RIS have initially emerged in developed areas - regions characterised by the presence of well-functioning services and infrastructures, specialised labour force, high level of human capital, and stable governmental, financial and educational institutions (as the Silicon Valley, see Saxenian, 1994) - there is an increasing evidence of RIS as well in lagging-behind regions which do not share the traditional RIS elements. This interesting phenomenon is gaining increasing attention in the literature (Lundvall et al., 2009; Coletti 
and Di Maria, 2015; Dhewanto et al., 2016; Fernández-Sastre and Martín-Mayoral, 2017; Guimon, 2017).

The present paper aims at contributing to the understanding of the phenomenon of RIS in emerging economies by analysing the dynamic process that has brought to the establishment of the mechatronic technological district in the Italian southern region, Apulia. Apulia is the sixth Italian region by area and population density, while it is the seventh region in terms of population. As many southern Italian regions, Apulia is classified as a lagging-behind region. In 2014, it's GDP per capita $37 \%$ lower than the EU average, with a $21.5 \%$ unemployment rate against a $10 \%$ EU average. Given these economic conditions, one could be surprised to find a high-technological intensive mechatronic cluster ${ }^{1}$, named MEDIS, in 2005 in the geographical area of Bari, the capital of Apulia where $31 \%$ of the Apulian population live.

We analyse the political and institutional process that has brought to the establishment of the Apulian mechatronic district. Through this case study, we want to address some more general research questions regarding how RIS can (and do) manage to emerge in lagging-behind areas; what is the role played by institutional and entrepreneurial factors; how this role and the related policies and the institutional governance have evolved over time.

This paper relates to the branch of literature that has increasingly questioned the widespread belief that technological change could only take place at the technological frontier in advanced economies, while firms from latecomer countries could only be involved in the mere acquisition and adaptation of existing technology produced somewhere else (Bell and Albu, 1999). This literature mainly focuses on the case of firms from disadvantaged areas undertaking innovative activities, on the underlying organisational systems and learning mechanisms at the base of their technological-innovative capabilities (Kim, 1998; Dutrenit, 2000; Figueiredo, 2003; Marcelle, 2004; Dantas and Bell, 2009). Compared to these contributions, our analysis is developed at a regional industry level. Therefore, we relate also to the literature that has focused on RIS and their ex-ante determinants (Chen and Guan, 2011; Buesa et al., 2010) and we extend it to the case of RIS emerging in developing areas, in line with previous contributions on innovation systems in developing economies (Giuliani and Bell, 2005; Ferretti and Parmentola, 2015; Zanello et al., 2015).

Finally, our paper relates to the literature on technological innovation systems which focuses on the policy instruments and organisational changes that are needed to support the development of novel technologies in a given institutional setting (Bergek et al., 2008; Musiolik et al., 2012). This approach focuses on the key role played by organisations and institutions in the emergence of an innovation system, but it has been mainly applied at a national level, without considering explicitly the governance of emerging local systems. Our paper enlarges this perspective by adopting a multi-level approach, which considers the historical evolution and coordination among national and regional institutions. We analyse how the governance and the related policies supporting the establishment of the Apulian mechatronic district has evolved over time, shifting from a national to a regional dimension. Indeed, our paper contributes to the increasing research that has acknowledged the importance of institutions and political framework for the development of technological innovation within a regional system. In particular, we focus on the dynamic evolution of the institutional framework, political process and policy instruments that have been implemented over a long period of time that lasted 
more than half a century to favour the emergence of an innovation system in a lagging-behind region.

This topic is relevant in light of the recent regionalisation of innovation policies (Fritsch and Stephan, 2005), and the related shift from traditional attraction strategies towards policies aimed at the creation of innovation systems. Developing innovative districts has been increasingly become a political priority to support economic growth at regional level. However, there has been a tendency to apply RIS supporting policies in a uniform way, without properly taking into account the related local specificities. Conversely, policies which resulted effective to support RIS in developed areas may not be transferable to lagging-behind regions which has to address specific criticalities (Hospers and Beugelskijk, 2002; Ebbekink and Lagendijk, 2013). This has brought the European Commission to increasingly adopt a 'smart specialisation strategy'. Developed, among others, by Foray and Van Ark (2007) and Foray et al. (2009), this approach aims at reinforcing the complementary dimensions of excellence and convergence objectives during the 2014-2020 periods. The new European regional innovation strategy relies on the idea that competitive advantages are not concentrated in specific regions, but that any region can have a competitive advantage with regard to specific resources (European Commission, 2012). In principle, any region can contribute to increase the EU knowledge-base, by focusing on a limited number of innovation and research priorities in those fields where the region 'can realistically hope to excel'. In this context, priority setting should ensure a "match between a top-down process of identification of broad objective aligned with EU policies and a bottom-up process of emergence of candidate niches for smart specialisation, areas of experimentation and future development stemming from the discovery activity of entrepreneurial actors" [European Commission, (2012), p.23].

This paper aims to provide some insights to understand how the smart specialisation strategy and regional innovation policies have been implemented and to assess whether they can be effective in promoting both excellence and cohesion objectives in lagging behind EU regions. Our contribution motivates from the consideration that policy measures should not be applied as a universal recipe without taking into consideration the cultural, institutional background as well as the specific industrial circumstances. To address this issue, we adopt a historical perspective that highlights how policies have evolved to address the evolving goals and the related specific shortcomings characterising a lagging-behind region. We believe that the case study can constitute an interesting approach to address these research questions, as the emergence of RIS in developing areas represents an issue which can be hardly separated from the economic, institutional and geographical context where it occurs (Yin, 2003).

The paper is structured in the following way. In Section 2, we review the main literature which relates to our paper. Section 3 describes the methodology adopted in this paper. Based on some earlier contributions on the institutional, industrial and societal ingredients of a RIS, Section 4 provides a conceptual framework where we formulate some propositions on the local dimension of innovation, the factors and conditions that are required for a RIS to grow in a less developed area. Section 5 describes the history of the emergence of an informal mechanical cluster and then the policy implemented by the Apulia regional government that brought to the establishment of the MEDIS. Section 6 critically discusses its potential value added in terms of innovation and economic development promotion. Section 7 concludes summing up findings and policy implications. 


\section{Literature review}

Technological innovation is a key-driver of growth at national, regional and firm level, and explains much of the income and productivity divergences among countries (Fagerberg et al., 2010; OECD, 2010). This evidence brought many scholars to analyse the determinants of technological innovation at a firm-level. As stressed by Bell and Figueiredo (2012), for decades the relevant literature focused on the technological learning process in developed economies and has discussed how firms that are already at the technological frontier organise their knowledge system to reinforce, sustain and renew their innovation capabilities that are already in place (e.g., Iansiti and Clark, 1994). Starting from the ' $80 \mathrm{~s}$, an emerging field of literature has questioned this paradigm to focus on the issue of technological change in developing countries and, specifically, on the process of knowledge accumulation and technological innovation in firms coming from latecomer countries (Bell and Albu, 1999, Bell, 2006). This literature analyses the different learning mechanisms characterising these firms. Bell and Albu (1999) stress that the understanding of technological innovation requires focus on their knowledge accumulation systems and on both the technological and organisational dimensions of the firm's innovation capability. Organisational theories stress that the firm's capacity to incorporate knowledge into its organisation system to develop innovation involves both internal and external learning mechanisms, calling for a deeper understanding of the external organisational and institutional changes that are needed to support technological learning and innovation (Edquist and Johnson, 1997; Bell and Albu, 1999). Other contributions stress that elements at the base of the innovative process are favoured by the technological proximity. This is largely explained by the relevance of tacit knowledge, which cannot be easily codified and can circulate only among people sharing a cumulative common prior knowledge, which is mainly generated in a learning-by-doing process through face-to-face interactions among subjects (Gertler, 1993; Maskell and Malmberg, 1999; Di Tommaso et al., 2006). With this respect, innovation has been increasingly conceptualised as the result of a systemic and interactive process based on the interaction among various local stakeholders which put the firm in relation with other organisations (Fagerberg, 2004). A famous way to represent these interactions is the Triple Helix model (Etzkowitz and Leydesdorff, 1996), which recognises a prominent role in the generation and transfer of knowledge across universities, industries and government agencies. This model builds on the concept of innovation system (Lundvall, 1992, Nelson, 1993; Edquist, 1997) which departs from the traditional conceptualisation of innovation as the result of a linear process but rather the result of a complex system of horizontal and vertical interactions among agents which share an adequate level of absorptive capacity, defined as the firms' ability to understand the value of new information and to assimilate it and adapt to their specific ends (Cohen and Levinthal, 1990; Lewin et al., 2011). In the innovation system approach, the recognition that innovation arises through the interaction of these three spheres highlights the relevance of geographical proximity in stimulating innovation. Geographical proximity is considered to play a crucial role in favouring intellectual, commercial and financial exchanges, knowledge spill over and the circulation of new ideas, thus heavily influencing the innovation process (Baldwin and Martin, 2004; Lehto, 2007). In the light of the relevance of the local dimension in the innovation process, the related literature progressively shifted from a national innovation system model (Nelson, 1993) towards a RIS model. A 
RIS can be defined as a system where firms are systematically engaged in interactive learning with other organisations in a well-defined area managed and governed by specific local institutions in a different way with respect to neighbouring territories areas (Cooke et al., 1997).

RIS have been increasingly analysed from different perspectives. While some researches focus on the impact of the RIS on firm's absorptive capacity, innovation and growth both at a firm and regional level (Kallio et al., 2010; Lau and Lo, 2015), other studies have investigated the RIS determinants, the key actors, networks and institutions at the base of the RIS and the processes required for an innovation system to grow at a local or regional level, such as networks among businesses, universities, regional culture, governance, as well as vertical and horizontal networking among industrial companies innovative resources and framework conditions (Chen and Guan, 2011; Buesa et al., 2010). This literature mainly focuses on RIS in advanced areas while, following some early papers that analysed the technological capabilities in firms located in developing countries (Katz, 1987; Bell and Albu, 1999), a recent strand of literature focuses on the emerging phenomenon of RIS in developing countries (Ferretti and Parmentola, 2015; Zanello et al., 2015).

Finally, particularly relevant for the purpose of this paper is the role of institutions and policies to foster the diffusion of a technology in a given context (Bergek et al., 2008; Markard and Truffer, 2008). This literature identifies several instruments and policies that institutions can implement to reduce uncertainty and financial constraints linked to the innovation process, facilitate coordination, promote cooperation and provide incentives for innovation through knowledge creation and transfer (Edquist and Johnson, 1997; Huggins and Kitagawa, 2011; Delgado et al., 2010). Among the policies, we can mention the support to human capital development via education and training policies, support to public research and to R\&D, support to start-ups promotion of network organisation, development of infrastructures (Audretsch and Feldman, 1996, Wolfe and Gertler, 2006).

\section{Methodology}

Our paper links to the previous research on RIS in emerging areas, and our goal is to explain the dynamic and evolving role played by public institutions to support the establishment of a RIS in a lagging-behind area. In order to address our research question on how a technological districts mange to emerge in a lagging-behind regions as well, we focus on the specific case study of the Apulian mechatronic district, with an attention to the political and institutional determinants at the base of its establishment.

We believe that the case study can constitute an interesting approach to address these research questions, as the emergence of a RIS in developing areas represents an issue which can be hardly separated from the economic, institutional and geographical context where it occurs (Yin, 2003). Yin also stresses the importance of analysing the case study according to a theoretical framework. Therefore, we first present a theoretical framework based on the main relevant literature where we formulate some general propositions on the local dimension of innovation and on the factors and conditions that are required for a RIS to grow in a less developed area. In particular, based on Ferretti and Parmentola (2015), we define taxonomy of government strategies to promote the establishment of a 
RIS in a less developed area according to the intensity of its involvement, the type of approach and policy instruments, and the governance level where policies are undertaken. Next, we apply this conceptual model to our case study. We discuss to which extent the emergence of the mechatronic cluster in Apulia has been driven by the establishment of an innovation system in the Apulia region. We discuss whether the process which brought to the MEDIS establishment is coherent with the underlying theoretical framework. We analyse which features identified by the literature as main RIS ingredients are present in the Apulia region, and whether public institutions behaved in line with the proposed taxonomy. This will help us to highlight the strengths and criticalities of the Apulian case, and its probability to success.

To address these issues, we broadly follow the technological innovation systems approach which focuses on the institutional and organisational changes that are needed for the emergence of novel technologies in a given area (Breschi and Malerba, 1997). This approach points to the relevance of the dynamic and interactive relations of a network of agents within a particular political and institutional context (Jacobsson and Bergek, 2012). Nevertheless, while this approach has been traditionally applied to analyse the process of technological innovation and diffusion at a national level, we focus on the dynamic role played by institutions and policies to support the consolidation of an innovation system in a circumscribed region. For this purpose, we adopt an event history analysis based on extensive desk documentary analysis and field interviews with selected stakeholders. ${ }^{2}$ The history analysis covers a long time period of over a half a century to describe the evolution of the institutional setting, the policy instruments and to identify the main key actors that have been involved in the governance of the system.

Finally, we discuss the strengths and weaknesses of the Apulian experience by developing a comparison with the successful innovation pole Mechatronics and Advanced Systems of Production (MESAP), located in the northern region of Piedmont. As argued, this is possibly a benchmark which the Apulian mechatronic district could look at, without disregarding the specificities of the Apulian industrial context.

\section{Conceptual framework}

In this section, a simple conceptual framework is proposed to explain the growth of a RIS in less developed areas. To do so we combine a set of preconditions and taxonomy of RIS supporting policies. In light of the summarised relevant literature which highlights the relevance of the local dimension in the innovation process, we first identify the main features that we retain to be necessary to favour the establishment of a RIS:

1 Presence of catalysing large enterprises and spatial proximity with small local enterprises: RIS usually emerge thanks to the pivotal role of large companies with a high level of technical specialisation which engages a process of knowledge transfer at a local level (Baptista, 2000; Parilli, 2009).

2 Presence of research centres: RIS are more likely to emerge in areas where there are research centres and universities with a high propensity towards technical and applied research. Universities can broaden their activities beyond their traditional educational and basic research missions. They can contribute to technological development by promoting the establishment of incubators for start-ups or by 
creating academic spin-offs through public-private partnerships (the so-called 'third mission').

3 Systematic interaction among actors: as highlighted by the famous Triple Helix model, to facilitate a process of collective learning and knowledge sharing, it is important to develop vertical or horizontal relations across universities, large and small enterprises industries and government agencies. These links can promote the circulation of new ideas, the spreading of innovative entrepreneurship culture, increase absorptive capacity, favour knowledge spill over and technological transfers (Bernardes and Albuquerque, 2003).

4 Actors' propensity towards internationalisation and diversification: the probability of the RIS to succeed depends both on its degree of internal interactions and openness to the outside the system (Asheim and Coenen, 2005). Territorially embedded systems with limited interactions with external organisations risk to incur in a technologically locked-in situations (Martin and Simmie, 2008). This point is strictly related with the previous one. Indeed, the more SMEs depend on the large enterprises within the system, the more likely it is that the decision making process within the process will be asymmetric and unbalanced. Consistently, Bacchiocchi et al. (2012) find that firms which highly depend on the leader company though subcontracting relations have a lower propensity to engage in research-intensive activities and face a lower probability of internationalisation.

Lagging behind regions often lack the elements identified as important factors for a RIS to success. In this case, central government and local institutions can play a key role to attract missing actors and promote their networking. Based on Ferretti and Parmentola (2015), we distinguish various RIS supporting strategies according to the intensity of government involvement, the type of approach and instruments it can adopt. Moreover, we extend this taxonomy with respect to another variable, which is the multi-governance level where policies can be implemented more effectively.

Table 1 Government strategy to enhance RIS: taxonomy

\begin{tabular}{lccc}
\hline & & \multicolumn{2}{c}{ Government involvement } \\
\cline { 3 - 4 } & & Direct & Indirect \\
\hline Government & Traditional & Case 1 & Case 2 \\
approach & Strategic & Case 3 & Case 4 \\
\hline
\end{tabular}

Source: Ferretti and Parmentola (2015)

These cases are not mutually exclusive and can occur consequentially at different stages of the RIS development process. According to this taxonomy, in a first top-down phase, the central government intervenes through traditional policies to attract new enterprises, human capital and financial resources in less developed areas. It can intervene directly, for instance though the establishment of new universities and state-owned enterprises (case 1), or indirectly: it can offer financial and tax incentives, advantageous labour market conditions, or it can develop infrastructures, export platforms or financial markets to induce large companies to establish their subsidiaries in underdeveloped areas (case 2). These policies are typically implemented at a national level to achieve short-term economic goals different from innovation, such as promoting social cohesion, increasing demand for local inputs or raising employment rates (Fosfuri et al., 2001). 
Nevertheless, positive economic effects driven by these policies risk to be temporary and to vanish if external investors localise in given area only temporarily, without establishing any cooperative relation with local actors. Therefore, the government should also create some favourable conditions to induce them to stay, by promoting stable interactive relations with local actors. These policies can be implemented only in a second phase, when specialised firms and universities are already in place at a local level, and can be combined with a bottom-up approach where existing local actors take the leading role in developing the RIS. We argue that this second step can be better implemented by the regional or local governments. Local institutions can act directly, for instance by fostering joint ventures among firms and local public enterprises or universities to favour technological and knowledge transfer that can improve organisational capabilities within the new public-private partnership (case 3). They can also intervene strategically in an indirect way (case 4), for instance by helping actors to attract national or international research funds; by favouring the establishment of new networks among the large companies and local actors; promoting training programs that can improve technical and managerial capabilities and to increase the absorptive capacity of local actors (Castellani and Zanfei, 2003; Morrison et al., 2008).

Figure 1 Process for a RIS in less developed areas: a conceptual framework (see online version for colours)

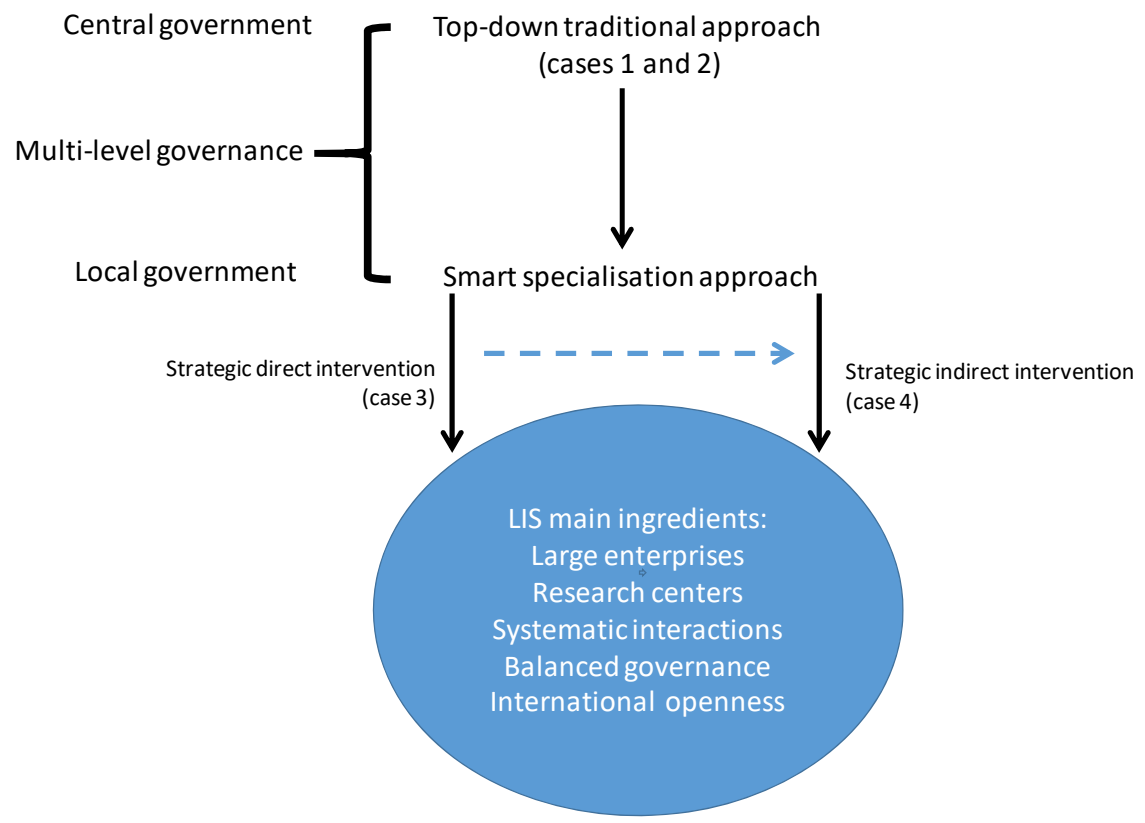

Source: Own elaboration

Overall, Figure 1 proposes a synthetic view of our conceptual framework. It illustrates the multi-step process required to bring in a less developed area the main ingredients at the base of a RIS, stressing both the multi-level dimension of its governance and the process of transition from case 3 to case 4, which the Apulia case attempts to engineer, and that the subsequent sections will further detail. 


\section{The Apulian mechatronic productive system}

Apulia is the sixth Italian region per territorial extension and it accounts for the $7 \%$ of the national population. Its capital is the city of Bari, which is the fifth Italian city by population. Classified as a 'Convergence' region during the 2007-2013 EU programming period, and as 'less developed' region over the current 2014-2020 period, Apulia is characterised by socio-economic indicators generally below the EU average and quite aligned with the rest of the South of Italy (also known as Mezzogiorno). Its regional economy has been structurally affected by the financial crisis and by the following economic recession. In particular, the Apulian GDP corresponds to $4 \%$ of the national GDP and $28 \%$ of the Southern Italy GDP, and these ratios remain stable over time. In Apulia, the GDP per capita was 30\% lower than the EU average in 2005, and this difference further increased after the great economic recession, resulting 37\% lower than the EU average in 2014. Similar ratios emerge when comparing the Apulian per capita GDP to the national GDP, while it is aligned with the average per capita GDP in the Mezzogiorno. The Apulian unemployment rate increased from $15 \%$ to $21.5 \%$ over the same period. The trends become particularly serious when looking at youth unemployment, which increased from $36 \%$ to $58 \%$. In 2014 , the unemployment rate in Apulia was slightly higher than in the Mezzogiorno (Table 2).

Indicators of innovation put Apulia among the moderately innovative regions of Europe, well behind regions of central and northern Europe (see Figure 2).

Figure 2 Clusters of EU regions by level of innovation - 2009 (see online version for colours)

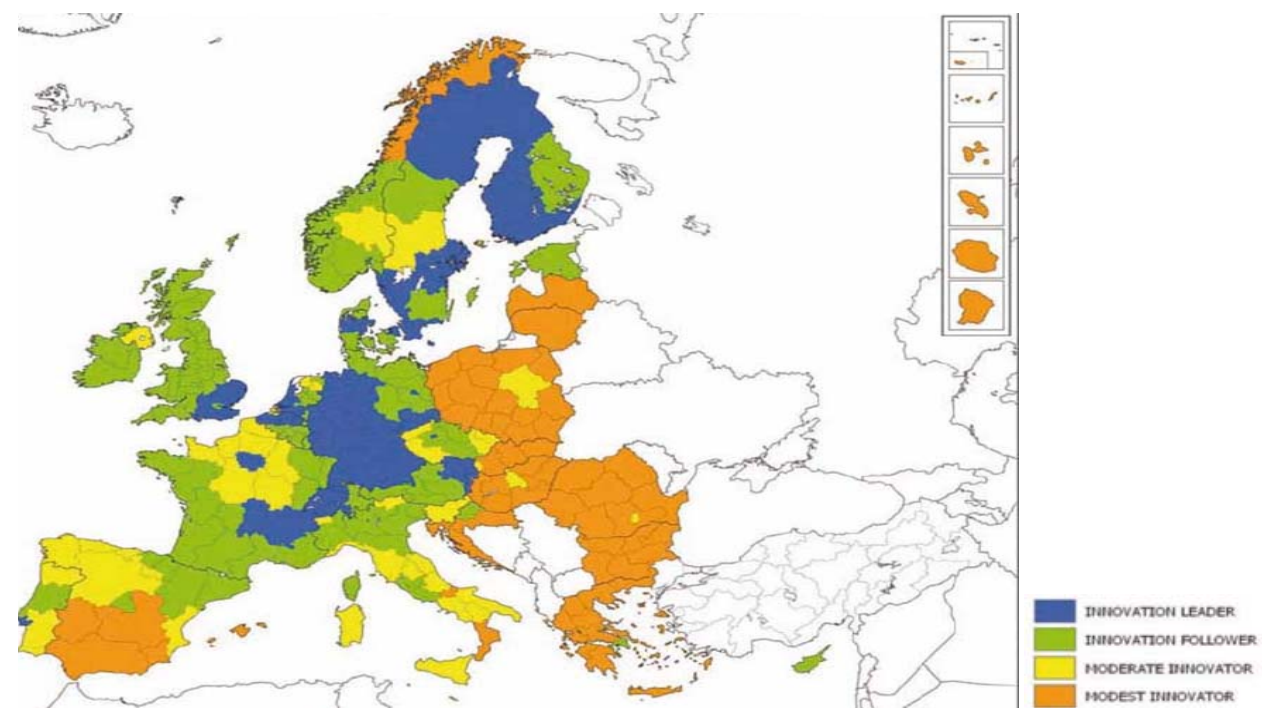

Source: European Commission (2012)

The total intramural R\&D expenditure of Apulia is $0.82 \%$ of GDP, against $1.31 \%$ and $2.03 \%$ for the entire Italy and the EU-28 respectively in 2013 . Unlike the rest of Italy and Europe, where approximately half of the total R\&D expenditure originates from the business enterprise sector, in Apulia $40 \%$ of $R \& D$ expenditure is imputable to higher education sector, while R\&D produced by enterprises represents only $19 \%$ of total expenditure (2010 data). 
How do research intensive systems emerge in less developed areas?

Table 2 GDP and unemployment rate in Apulia: a comparative perspective

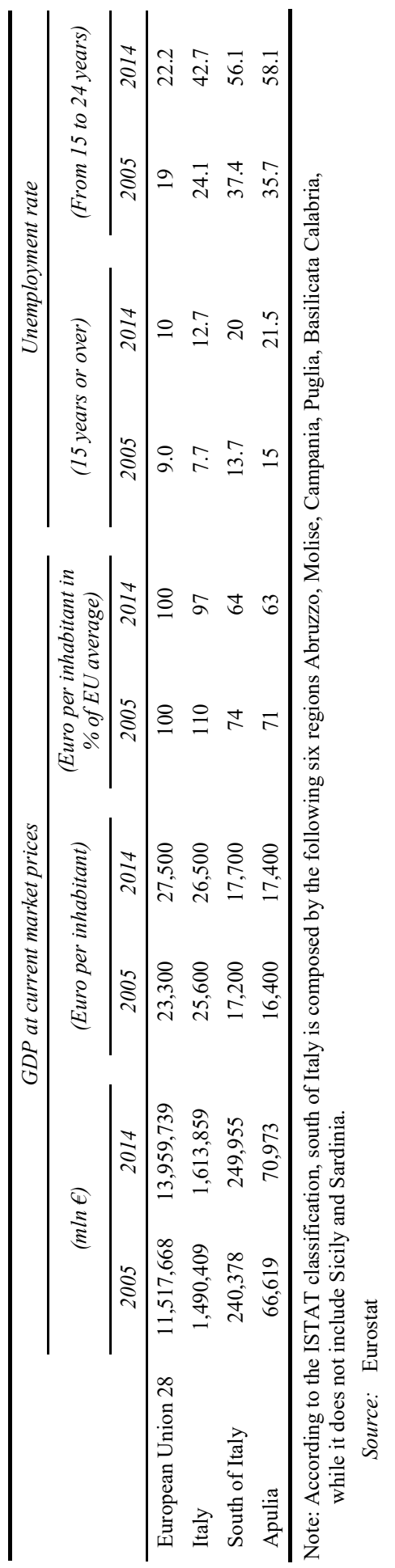


Figure 3 Total intramural R\&D expenditure by sectors of performance - 2010 (see online version for colours)
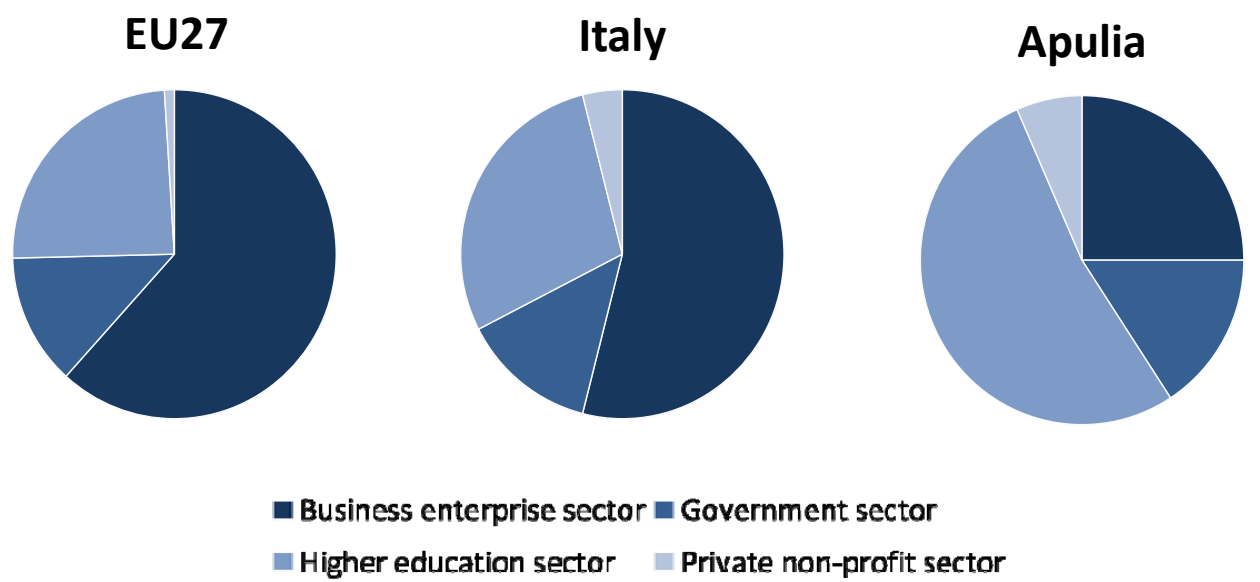

Source: Authors' elaboration based on Eurostat (2013)

\subsection{Apulian mechanical industry}

Mechatronics can be defined as the joint and simultaneous interaction between mechanical, electrical and computer engineering. Mechatronic solutions find applications in the most advanced productive sectors of mechanics, particularly automotive sectors, as well as aerospace and biomedical sectors. Given this definition, in this section we briefly introduce the role played in the Apulian economy by the mechanical and electronic sectors closely related to mechatronics.

In Europe, together with Germany, Italy plays a leading role in the mechanical sectors, whose productive activities concentrate in the north-east and north-west of the country, with a partial exception of Apulia. Indeed, Apulia, and its capital Bari in particular, shows a long-standing industrial tradition in mechanical engineering. Nowadays, the province of Bari counts plants and research centres of various world leaders in the automotive industry, among them Fiat, Magneti Marelli, Bosch, Getrag. In 2013, both in Italy and in Apulia around 9\% of total enterprises operated in the manufacturing sectors. In Apulia, the sector 'manufacture of machinery and equipment' is the most relevant mechanical sector in terms of number of enterprises and employees, while the 'manufacture of motor vehicles, trailers and semi-trailers' is the most relevant in terms of value added and operating revenues. While from the aggregate economic data presented in Table 2, Apulia shows slightly worse indicators compared to the Italian Mezzogiorno, a closer look at the industrial economic indicators highlights the relevance of the Apulia region in the southern Italy. 30\% of the southern enterprises and employees are located in Apulia, where around $30 \%$ of the industrial added value is generated. This share increase to $37 \%$, when looking at the 'manufacture of machinery and equipment' sector, where Apulia shows a relevant technological specialisation. 
Table 3 Manufacturing sub-sectors: key data for Italy and Apulia (2013)

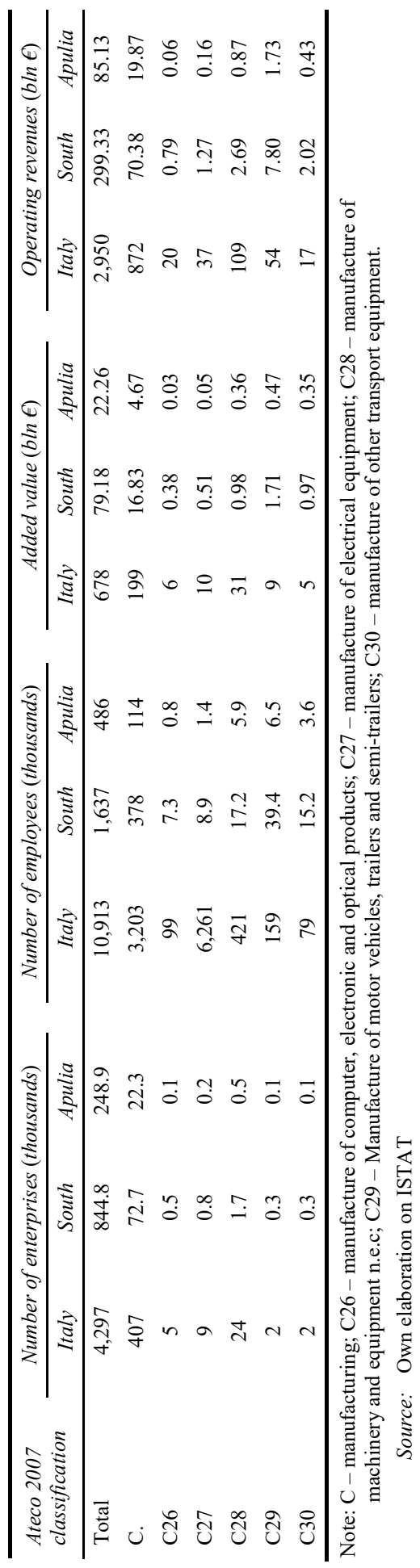




\subsection{Establishment of large enterprises and research centres in the area of Bari}

The establishment of the mechatronic cluster in the area of Bari is the result of a multi-step process initially driven by the government initiative. The Italian Government played a crucial role during the late 1960s and beginning of 1970s to foster employment and economic growth in the south of Italy by attracting in the Apulian region some large enterprises that were missing from the territory. In 1972, the state-owned company ENI opened a new plant of its controlled subsidiary Nuovo Pignone - Mechanical and Foundry Spa, specialised in the production of machinery and equipment for the oil and petrochemical industries. In the same period, the private companies Magneti Marelli Powertrain and Fiat, both producing components for the automotive industry, reacted to the national incentives aimed at attractive labour intensive plants in the south of Italy and opened new plants in Bari during the first half of the '70s. SKF Industrie undertook another major greenfield investment in Bari in 1972. ${ }^{3}$ Over the same years, both public and private centres for research and development have been founded. The first important research centre that has been opened in the Apulian territory is the Fiat Research Centre (Centro Ricerche Fiat - CRF) with the purpose of developing processes and products for the automotive injection systems for the Fiat group.

A second phase of industrial development took place at the beginning of the ' $90 \mathrm{~s}$, through the establishment of new research centres and companies with a strong commitment to research and innovation in mechanical engineering. Also this second phase of expansion was driven by an active role of the Italian Central Government. Nevertheless, this top-down approach started to be combined by a bottom-up initiative on behalf of private enterprises that were already established in the territory and acted as important catalysers. Notably, the settlement in 1994 of Bosch, the German multinational company producing automotive components for the world car industry, in the industrial area of Bari is strictly connected to the R\&D activity performed by the Fiat Research Center. ${ }^{4}$ After setting its own plant in Bari in 1994, Bosch acquired also Allied Signal, a company producing braking systems with a plant in Bari. On the research side, after establishing Diesel Technologies Italy, a joint venture between Bosch and Magneti Marelli which now belongs entirely the German group, Bosch established in Bari also its own research centre, Centro Studi Componenti per Veicoli S.p.A. in 2000. Starting with a staff of less than seventy people, it has reached today 214 employees, including 160 engineers recruited from local universities.

In 1996 Getrag, the world leader in the production of transmission systems for the automotive sector chose to settle a new plant and a R\&D unit in Bari. This choice was driven by various factors: the local mechanical engineering tradition and the availability of skilled and relatively convenient labour; the presence of other north European and German enterprises, and the significant public contributions granted by the Italian government through a 'programme agreement' 5 .

On top of major national and foreign enterprises, also new medium mechanical enterprises with a strong innovative vocation and high-technology content established in the area of Bari. Among them, we mention Masmec, MerMec and Itel Telecomunicazioni, which reached the size of medium enterprises, thanks to international competitiveness and diversification of their product portfolio. The innovation capacity of these local firms has been recognised by some national and international awards (see Section 4.2). 
On top of high-tech enterprises with a strong innovative vocation, nowadays the Apulia region is characterised by some remarkable research centres: more than 20 institutes belonging to the National Council of Research (CNR), including the National Laboratory for Nanotechnology, the Institute for Microelectronics and Microsystems, the Institute for Industrial and Automation Technologies. The CNR manages the consortium Sintesi, a public-private research company in robotics and production systems. Another public-private research centre is Laser Innovation Technology Transfer and Training centre, which focuses on laser material processing, electrical-optical sensors and micro devices. Other public actors of the regional public research system include universities, notably the Polytechnic University of Bari which was set up in 1990 and in 2012/2013 counted 10 thousand students.

\subsection{Orientation towards innovation: the Apulia RIS}

The first step of a government national policy attracting important large enterprises and some private and public research centres within the area of Bari was necessary, though not sufficient, to promote the growth of a RIS. This policy was mainly oriented to employment and GDP growth targets, while they were not specifically tailored to achieve innovation goals. With the new millennium there was a change in the Apulian political strategy which coincided with the regionalisation of the innovation policies and with a change in the governance of the RIS of Apulia. In 2005 the new regional government decided to set up a system of agencies, including the newly born ARTI (Regional Agency for Technology and Development) and other two regional bodies: InnovaPuglia S.p.A. and PugliaSviluppo S.p.A. The former is in charge of the implementation of egovernment policies and ICT infrastructure investments, while the latter is in charge of the promotion of business competitiveness, delivering Structural Funds' grants and engineering financial instruments to support entrepreneurship, innovation and internationalisation. PugliaSviluppo works as one-stop shop for enterprises; it supports them during the whole process going from the project idea development, through the procedures to get administrative permits, up to the project final approval. PugliaSviluppo operates as intermediary of other EU financing instruments specifically targeted to favour the access to credit of non-bankable SMEs. Furthermore, in 2013 PugliaSviluppo has been authorised by the Central Bank of Italy as financial agency which can deliver microcredit to SMEs drawing on its own capital. Moreover, PugliaSviluppo is currently the only regional intermediate body in Italy which disburses in advance up to $90 \%$ of the structural funds' grants (in two tranches), against a suitable bank guarantee by the beneficiary firm. In total, financing instruments initiated so far by PugliaSviluppo supported nearly EUR 2 billion of investments, of which EUR 1.04 billion related to programme agreements. The agency played a key role to convey to the mechatronics enterprises in the area of Bari significant resources to support new investments and R\&D projects (Programma operativo regionale POR 2000-2006, Measure 4.18).

Given this change in the Apulian institutional setting, one should not be surprised by the fact that two of the six southern production systems specialised in the production of high technology goods and services are located in Apulia. ${ }^{6}$ In the next section we focus on the Apulian mechatronic cluster, named MEDIS. 
Table 4 Contracts signed under the agreement program POR Puglia 2000-2006 (measure 4.18)

\begin{tabular}{lccccc}
\hline & \multicolumn{2}{c}{ Industrial investments } & & \multicolumn{2}{c}{$R \& D$} \\
\cline { 2 - 3 } \cline { 5 - 6 } \cline { 5 - 6 } & $\begin{array}{c}\text { Admitted } \\
\text { program }\end{array}$ & $\begin{array}{c}\text { Public } \\
\text { contribution } \\
\text { Misura } 4.18\end{array}$ & & $\begin{array}{c}\text { Admitted } \\
\text { program }\end{array}$ & $\begin{array}{c}\text { Public } \\
\text { contribution } \\
\text { Misura } 4.18\end{array}$ \\
\hline Magneti Marelli & $49,605,000$ & $23,884,348$ & & 11,501 & 4,601 \\
Getrag S.p.A. & $25,547,422$ & $12,581,130$ & & 11,623 & 4,633 \\
Mec S.p.A. & $1,608,603$ & 936,640 & & 2,156 & 862 \\
Centro Laser s.c.a.r. & 433,516 & 261,349 & & 413 & 165 \\
Planetek Italia s.r.l. & 263,603 & 157,735 & & 1,355 & 520 \\
Icam s.r.l. & $1,744,294$ & $1,115,858$ & & 1,690 & 574 \\
\hline
\end{tabular}

Source: Invitalia (2012)

\subsection{Fostering interactions: the establishment of MEDIS}

Albeit important to attract large enterprises and the capital required to promote a progressive focus towards research and innovation activities, the mechanical system that has grown up around the area of Bari was still lacking a crucial ingredient of a RIS: the intense interaction among enterprises and research centres. To overcome this missing ingredient, important steps have been undertaken by ARTI to promote interconnections among different actors. For this purpose, the agency has created, within local universities, a network of Industrial Liaison Offices (ILOs) aimed at promoting technological transfer, the generation of spin-offs, and the institutionalisation of other public-private initiatives, such as the creation of consortia among various actors, named Technological Clusters (TCs).

In 2007 ARTI drafted the TC's statute and the consortium MEDIS S.c.a.r.l. (Distretto Meccatronico Regionale della Puglia) was established. The consortium involves now all the main public and private actors belonging to the local productive and research system, with overall governance equilibrium between the two components. Public-sector participants own $51 \%$ of the consortium shares, private ones (including two public-private research centres) $49 \%$. All member enterprises have a fairly similar share of equity, regardless their size or turnover. ${ }^{7}$ The balance between public and private interests is reflected in the composition of MEDIS board, with two representatives of public actors and two representatives of private actors. MEDIS's stated mission is to overcome the major weaknesses of the Apulian mechatronic sector, such as: the relative small size of the Apulian firms and of their business research, the dependence of many plants on multinational strategies, the relatively peripheral location compared to central Europe and Asian markets, and production costs significantly higher than competitors from Eastern Europe and beyond. MEDIS identifies in its statute several pathways based to overcome these problems:

a promote the study, research, development for the industrialisation of technologies and prototypes in the field of mechatronics, and the marketing of results to shareholders 
b support the planning, organisation and carrying out of industrial research and pre-competitive development of members

c training, upgrading, professional training of qualified researchers and technicians in the fields of activities of interest of the MEDIS members

d support technology transfer programs in favour of local small-medium enterprises (SMEs).

Figure 4 Simplified representation of the multi-level governance of the Apulian innovation system (see online version for colours)

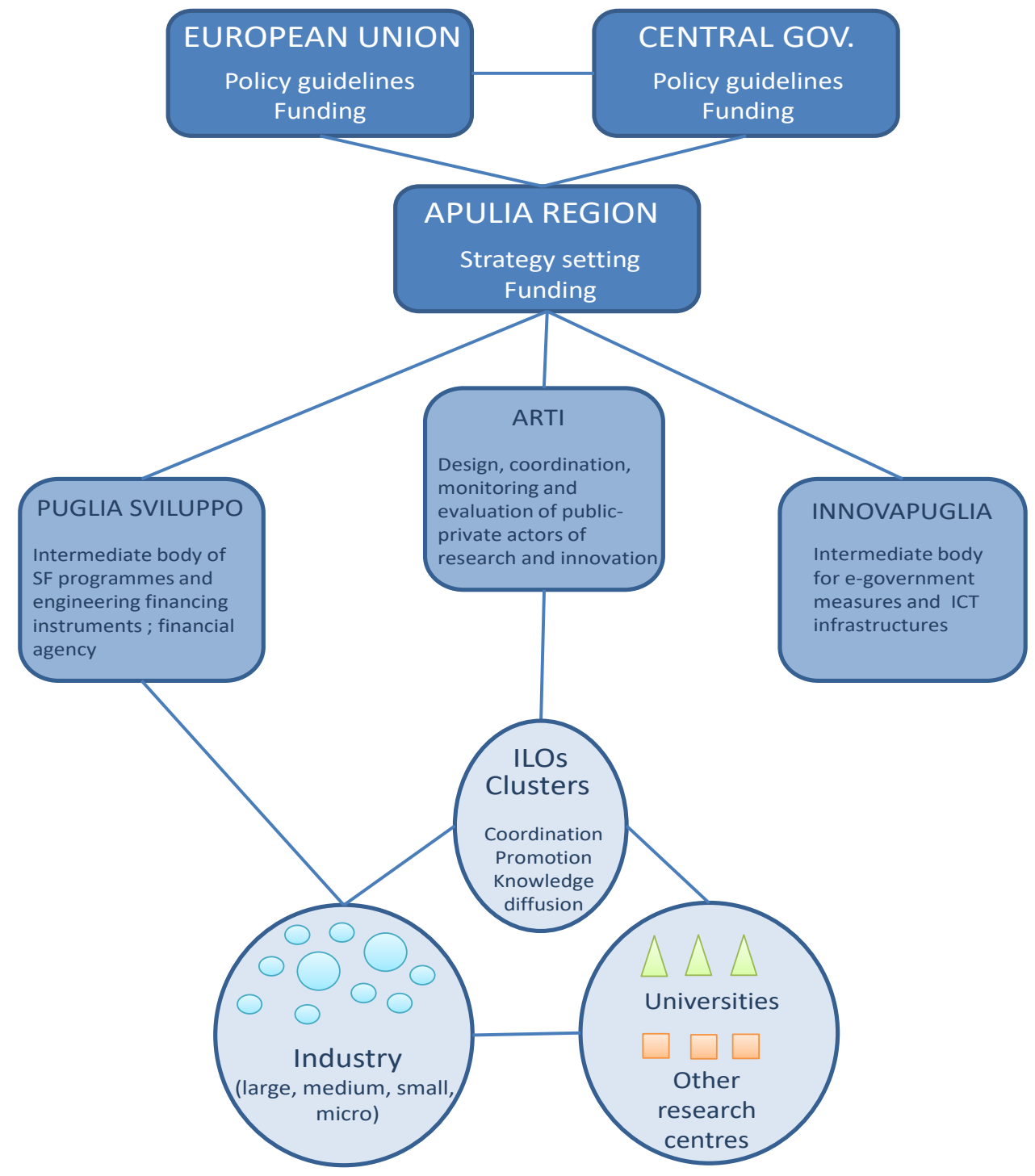


For the period 2011-2015, MEDIS decided to focus its activities on three intervention areas, selected after a consultation process with its members and ensuring coverage of all their activities:

1 Development of advanced minimally invasive diagnostic and radiation oncology systems.

2 Development of innovative mechatronic security systems (wired and wireless) for railway, aerospace and robotic applications.

3 Development of innovative technologies for the reduction of emissions, fuel consumption and operating costs of heavy-duty engines, in anticipation of the new community rules in this field.

MEDIS is responsible for obtaining public financing and providing support mainly in terms of project management and coordination. Each research project is implemented by a group of MEDIS members, usually in collaboration with other actors operating on a regional, national and international level.

\section{A critical evaluation of the MEDIS results}

When evaluating the performance of the Apulian MEDIS we should take into account that its establishment in 2007 coincided with the international economic crisis, which affected the mechanic and electronic enterprises located in Bari as well, as shown by the significant decline in exports. It is not easy to identify a common pattern across different sectors. Some of them (computer, electronic, electrical equipment), show declining exports even before and after the years of the financial crisis, which has intensified some structural problems. For other sectors, the crisis had a contingent effect, as exports tend to decline after 2008, while they increase during the last years. It is the case of the automotive industry, which highly depends on the business cycle (Figure 5).

Figure 5 Value of export in selected manufacturing sectors in the province of Bari ( $\mathrm{mln} €$ ) (see online version for colours)

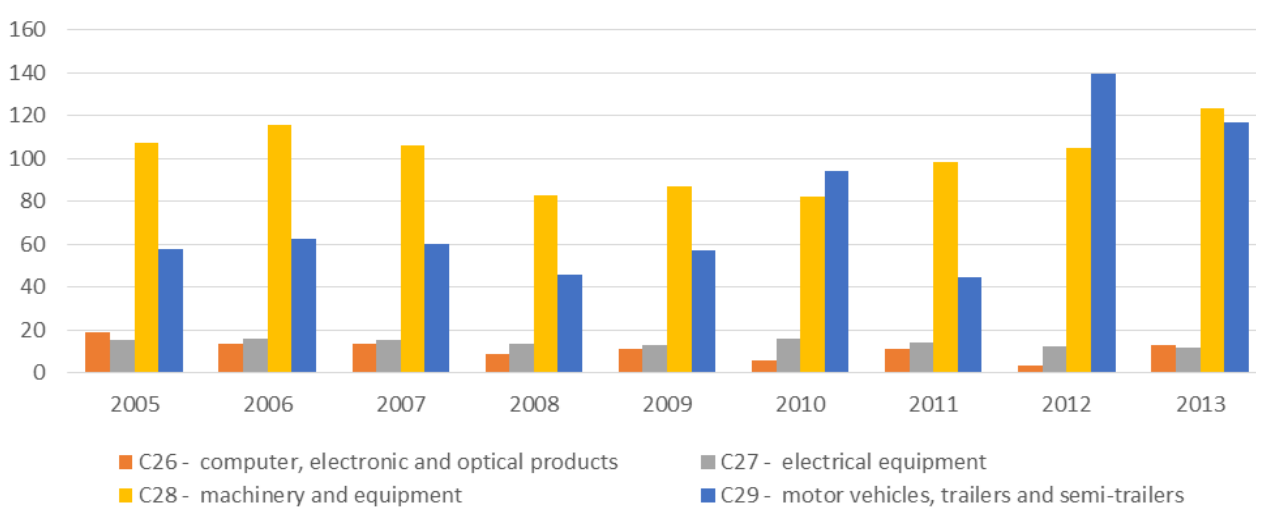

Source: Own elaboration on ISTAT 
This trend is also reflected in the weight sector production held in Bari over national total sector production. In particular, we observe an almost continued erosion of the share in the case of computer and electronic equipment, while the transport vehicle manufacturing sector shows and increasing trend after 2011 [Figure 6(a)]. A comparison with the southern Italy aggregated data show that, on average, Apulia contributes for the $20 \%$ to exports of the machinery sector which strictly relates to the mechatronic activity. Percentages decrease below the $10 \%$ when looking at the other manufacturing sub-sectors.

Figure 6 Bari-Italy ratio of the value of exports by selected manufacturing sectors (see online version for colours)

$2.00 \%$

$1.50 \%$

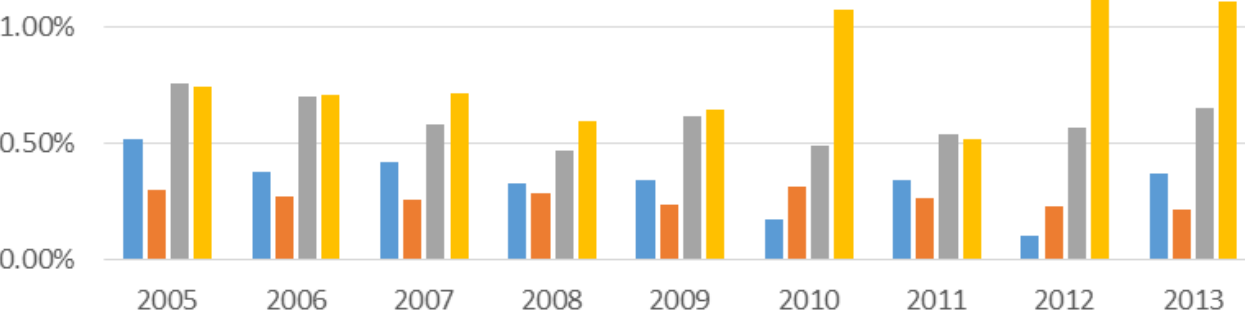

- C26 - computer, electronic and optical products

- C27 - electrical equipment

(a)

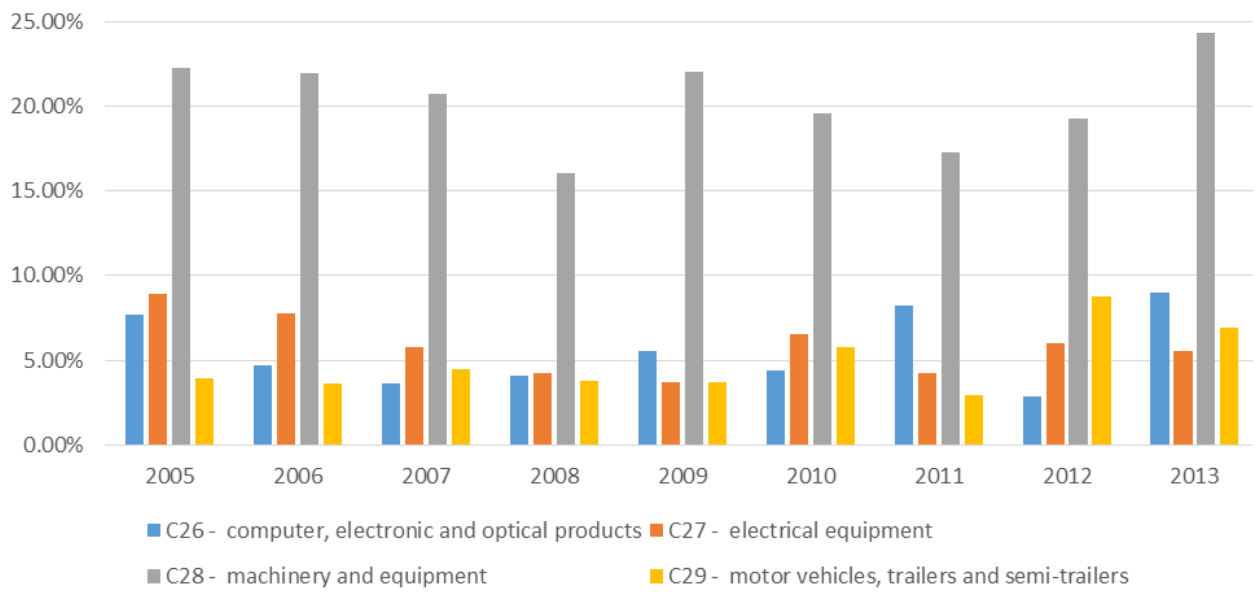

(b)

Source: Own elaboration on ISTAT 


$$
\text { 目 }
$$


When focusing on the firms belonging to the MEDIS, we observe that, in spite of the financial crisis, they increased their operating revenues and EBITDA (Table 5). Table 5 also compares the economic and financial data of the firms that belong to the MEDIS with other mechanical firms which operate in the area of Bari but which have not been formally included in the MEDIS district. The MEDIS enterprises are on average bigger in terms of assets and number of employees, they show a better financial performance in terms of revenues, EBITDA and return on sales (ROS). This difference was in place even before the MEDIS establishment and it slightly increased after its establishment, suggesting that the financial crisis affected more non-district than district firms.

\subsection{Results on innovation: Apulia and MEDIS}

The regionalisation of innovation policies and the promotion of technological clusters brought to some important results. In spite of being lower in absolute terms, the intramural expenditure in R\&D (as percentage of the GDP) increased between 2005 and 2013 more in Apulia than the EU average in all the considered sectors, a part from the higher education sector. When looking at the business enterprise sector and at the government sector, Apulia performed better than Italy as well.

Interestingly, also the Apulian intramural R\&D per capita expenditures show higher rate over the period 2005-2013 in the business enterprise sector and notably in the government sector $(+55 \%$ against $+5 \%$ and $+19 \%$ in Italy and EU-28 respectively).

The fact that $82 \%$ of the overall intramural R\&D expenditures of the southern Italy comes from Apulia is a very interesting indicator of the dynamism of this region. These percentages even increase when looking at the $R \& D$ expenditures coming from the Government and Higher Education sectors and point out to the relevance of innovation strategies in the Apulian regional policy. The strong divergence between Apulia and the Mezzogiorno in terms of R\&D expenditures can be better understood in the light of the Apulian fairly good local industrial context, its strong regional commitment to innovation strategies. The change in the regional institutional setting governing innovation-oriented activity has contributed to promote public-private collaboration, such as Technological Clusters, and has improved the effectiveness in the management of the European Structural Funds, whose volumes have been increasingly allocated to R\&I priorities. Differently from other Southern regions, like Calabria or Sicily, Apulia performed better than Sicily in managing and spending the European Regional Development Fund (ERDF). It managed to overcome some deficiencies in relation to the overall ERDF framework (e.g., policies, strategies, regulations), to the ERDF actors (e.g., cooperation/coordination between the concerned actors, and staff capacities), and in relation to ERDF monitoring and financial control. As a result, in the 2007-2013 European Union Structural Fund programming period, Apulia managed to spend 3.4 billion of its over 4.1 billion euro budget, increasing its spending target from $77.4 \%$ to $82.4 \%$. Not surprisingly, Apulia and has been called a model of spending by European Commissioner for Regional Policy Corina Creţu while, conversely, Sicily managed to allocate 2.4 billion out of its 4.3 billion total endowment and failed to meet its spending target of $64.1 \%$. 
Table 6 Intramural R\&D expenditure by sectors of performance

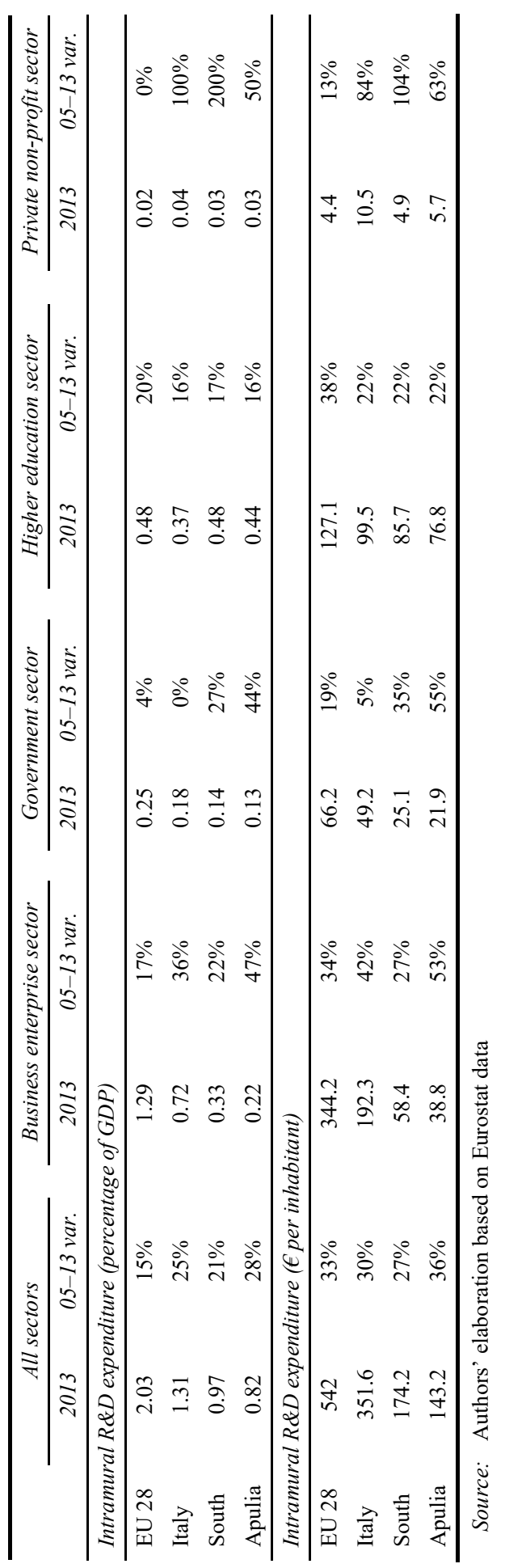


Within this framework, we look more specifically at MEDIS. According to interviewees, the training of about sixty young researchers and technicians in the three priority technological fields covered by MEDIS and coming from the local universities represents an important result that can be imputed to MEDIS. MEDIS is also contributing to reinforce the relations and synergic competences within and outside the cluster in three principal ways:

1 fostering partnerships and collaborations with external subjects ${ }^{8}$

2 promoting collaboration agreements directly involving external actors in its research projects $^{9}$

3 attracting public funding to promote some major interdisciplinary research projects.

After its establishment, MEDIS faced some problems to get public financing to support several projects specifically targeted to one of MEDIS three priority fields, and participated by all the MEDIS private actors, research centres and universities.

Though most of them have not delivered any output yet, a few illustrative data can be provided. The know-how that has been produced over the 2008-2010 period by some of MEDIS members includes:

- 21 new products developed by MerMec, Itel, Masmec and the research centre Sintesi. Just to mention some of them: MerMec has developed led optical system for railway use, Masmec a biomedical liquid handling workstation for molecular diagnostics, Itel a robotic system for placing the patient in radiotherapy, the research centre Sintesi an encoder laser for measuring mechanical and structural deformation.

- 19 applications realised by MerMec, Itel, Sintesi, the Polytechnic Institute of Bari and the University of Bari. Examples are a new software modular platform for ex-ante monitoring of railway assets (MarMec), Sensors and laser micro-machining for engine applications and manufacturing, plus a new laser sensor for NOx emissions monitoring (University of Bari), and software for automatic design of electrical machines with permanent magnets (Polytechnic Institute of Bari).

- 12 patents, most of which European and international, obtained by the three Apulian companies, Sintesi and the two universities;

- 69 new permanent employees and more than 100 fix-term employees in the three Apulian companies Itel, Masmec and MerMec.

It is worth to mention that MERMEC Group received the prestigious 'Oscar of Photonics' 2011 for T-SIGHT 5000 Tunnel Wall Inspection System. Technology Review, the official MIT's magazine about innovation, selected MERMEC T-Sight 5000 as one of the 50 most innovative solutions able to change the world.

At a more aggregate level, one may look at the dynamics of knowledge creation in the local context, like the number of patent applications made by residents in the province of Bari to Italian patent offices during the last 20 years. Numbers can be hardly compared due to their different scale (patents in Bari increased from a number of 30 in 1993 to 170 
in the year 2013, while Italian patents increased from 8,100 to 9,200 over the same period). Nevertheless, it can be useful to observe that the $+174 \%$ variation registered in the area of Bari is higher than the change occurred in Apulia and in Italy (respectively $146 \%$ and 14\%) (Figure 7). In the 2008-2013 period, after the MEDIS establishment, patent applications surged by $49 \%$ in Bari ( +40 patents), versus a $12 \%$ in the rest of Apulia ( +20 patents) and in contrast to a $-3 \%$ reduction in Italy ( $-3,000$ patents). $72 \%$ of all Apulian patent applications are ascribable to the province of Bari.

Figure 7 Patent applications in the mechatronic industry Italy, Apulia and the province of Bari (see online version for colours)

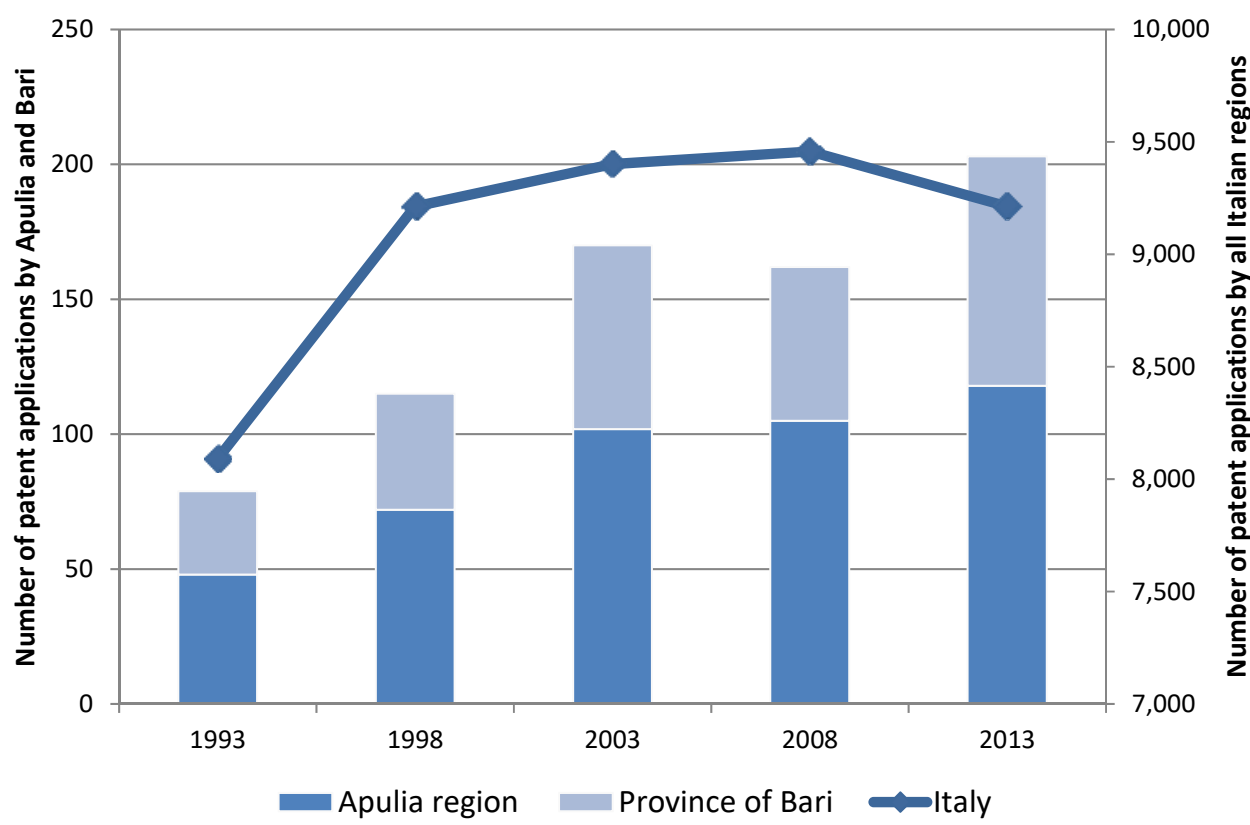

Source: Authors' elaboration based on the Italian Patent and Trademark Office data

The trend is even more pronounced when considering utility models, another juridical form of intellectual property protection which usually applies to changes in the functionalities of already existing processes or products rather than on new ex-novo inventions. Similarly to the patent system, also the utility model grants a temporary statutory monopoly over an innovation, but usually has a shorter term (often 6 to 15 years) and less stringent patentability requirements.

While being lowest in absolute terms, the number of utility models applications in the province of Bari has undergone a $193 \%$ increase during the $2008-2013$ period $(+40$ utility models). This growth rate has been higher than the $+92 \%$ increase recorded in the whole region (around +70 utility models) and much higher than the $21 \%$ Italian increase (slightly less than 500 utility models) (Figure 8). 
Figure 8 Applications for utility models in the mechatronic industry in Italy, Apulia and the province of Bari (see online version for colours)

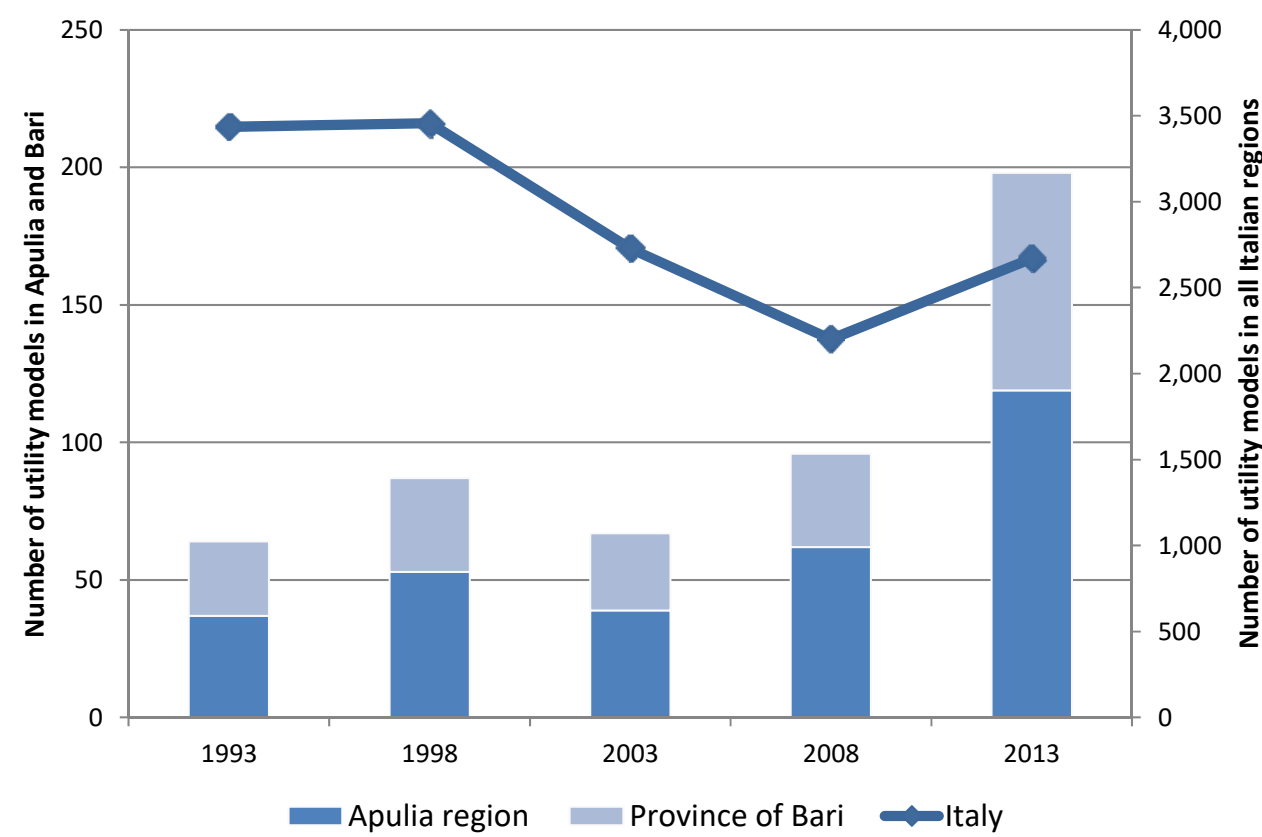

Source: Authors' elaboration based on the Italian Patent and Trademark Office data

\subsection{Discussion: weaknesses and opportunities of future development}

Previous analysis shows that the MEDIS presents some of the ingredients that we have identified as crucial for a RIS to grow steadily. In this section we discuss some weaknesses that could prevent the MEDIS to become the stable base for a long-term oriented innovation system, and we propose some potential remedies.

One of the potential shortcomings which risk to affect the future development of the MEDIS is its limited openness outside the cluster (Asheim and Coenen, 2005; Martin and Simmie, 2008; Bacchiocchi et al., 2012). One of the conditions for a RIS to grow in the long-term is the construction of a plurality of international business relations. In the MEDIS case, some of the major players belong to international multinational companies which grant to access to the more advanced research and technology context of Piedmont or Germany. Moreover, local universities and research centres have built some relations with foreign research institutes, and some of the highly specialises local players compete at a global level and export their high-tech products all over the world. However, these international relations were existing even before the creation of the MEDIS, and are still based on the individual relations of the single components. MEDIS launched some initiatives aimed at fostering partnerships and collaborations with external subjects, such as the promotion of collaboration agreements directly involving external actors in interdisciplinary and pre-competitive research projects. These initiatives should be reinforced in the future. 
MEDIS would also benefit from a wider involvement of local SMEs through the supply relationship between large MEDIS enterprises and the SMEs and through training programs aimed at promoting vertical knowledge spill overs. On this issue, we recall that one of the merits of the Apulian RIS has been to increasingly address financial resources to support research and innovation investments, instead of giving a generalised public support to investments without any specific qualification. Public funding prevented the two German corporations (Bosch and Getrag) to delocalise their plants away from Apulia, managing to support both employment and research activities in spite of the crisis of the automotive sector. However, the positive response of the local private sector on the basis of such an important public sector endeavour should not be really surprising. Conversely, the positive economic spill avers outside the district itself remain less evident. Previous data show that the difference in profitability among district and non-district enterprises has increased after the establishment of the MEDIS. This calls to question how effective the MEDIS has been in promoting and establishing stable interactions with small local enterprises outside the district. In other terms, is not clear to which extent the presence of important companies in the area of Bari has been driven mainly by public support or rather by local comparative advantages, such as the presence of skilled labour force or stable subcontracting relation with specialised local enterprises. Would international multinational companies still find convenient to localise their plants in the area of Bari even without the support of public funding? What are the local factors of comparative advantage that may induce these companies to abstain from delocalisation strategies? The literature stresses how important absorptive capacity and the diffusion of tacit knowledge are for a technological cluster to grow (Etzkowitz and Leydesdorff, 1996; Bernardes and Albuquerque, 2003). This suggests that innovation policy should focus more on the relations between interacting players and organisations rather than on the single players per se (Lundvall et al., 2009). Without a clear strategy oriented at promoting knowledge spill over and technological transfer through partnerships and involvements of local enterprises in the supply chain, the positive impact of the regional innovation policy on the local economy may be temporary, as multinational enterprises may decide in the future to delocalise in other areas.

While, during the crisis the strategies implements by the Apulian region have been mainly addressed at supporting employment and avoiding the closure of important plants, in the future policies should focus more on increasing the number of players involved in the mechatronic cluster and to promote projects aimed at increasing labour specialisation and human capital improvement. The training of new researchers and engineers in mechatronics sciences promoted by MEDIS and their employment in regional enterprises or research centres can be a way to favour such spread of knowledge. Additional mechanisms favouring firms' absorption of new knowledge and their innovation capacity are needed.

According to interviews and documentary evidence we have collected, MEDIS itself admits that, for the cluster's potentialities to fully show themselves and produce wider effects, the model of the Mechatronics Technological Cluster needs to evolve. In particular, MEDIS should become a promoter of innovation not only among its members, but for the local productive system in general.

In its 2011-2015 strategic plans, MEDIS acknowledges the importance for the consortium to acquire a stronger strategic role for socio-economic development, primarily by giving itself an ILO. Following the example of several ILOs already existing in Europe, and integrating itself in the network of regional ILOs established by ARTI 
within the main universities, ILO-MEDIS will be entrusted to increase the overall commercial and economic impact of research activities. This objective will be pursued by providing services to the creation of spin-offs, information to enterprises about existing technological opportunities and support for patenting.

Moreover, MEDIS is currently reconsidering the number of companies to be involved in the consortium and the modalities of involvement. MEDIS is in principle open to new members, but, since its foundation, its memberships has been limited to a small number of medium-large well established private-sector players, thus excluding all small companies lacking a noteworthy research laboratory. While it is true that over the past few years some companies have been growing and have equipped themselves with a dedicated R\&D division or laboratory, so that they could now strive for being admitted in the consortium ${ }^{10}$, they still represent a very limited number.

The decision of limiting MEDIS membership to highly innovative firms and R\&D centres aimed at putting excellence in the foreground. While the increase of the firms belonging to the cluster may raise the coordination costs among agents, limiting MEDIS membership could risk constraining the achievement of economic convergence objectives. Against this risk, an adequate process of knowledge diffusion from the MEDIS to the local SMEs, while keeping the number of MEDIS members limited, can favour the establishment of new start-ups and the increase of innovation within other smaller enterprises. The reinforcement of the entire cluster, rather than of few companies belonging to it, would be beneficial not only to the majority of small companies having less capacity to carry out significant research projects on their own, but also to the most innovative enterprises, which would then rely on a stronger local supply chain, able to provide improved technological applications and solutions. PugliaSviluppo usually asks large companies benefitting from a 'programme agreement' to involve in their activities local SMEs, but this is not a binding condition for funding. Hence there is no guarantee that collaborations actually take place and that knowledge is transferred.

Is there experience elsewhere of a more opens and flexible system for the development of technology transfer? A possible benchmark has already been identified by MEDIS itself: it is Mechatronics and Advanced Systems of Production (MESAP), an innovation pole promoted in 2009 by the Piedmont Region, in northern Italy. As the region where Fiat was born and developed, Piedmont shows deep-rooted industrial and innovation traditions, thanks to is world class excellence in specific sectors or highly skilled niches. MESAP is the body chosen by the Piedmont region to link public and private actors and stimulate their collaboration on applied research projects focused on technological development ${ }^{11}$. Hence MESAP and MEDIS broadly share the same mission. Like MEDIS, MESAP has identified a small number of horizontal technological domains on which focus research activities, which are relevant to different industrial sectors (automotive, aerospace, biomedicine, railway, chemical, etc.).

Thanks to MESAP, large and medium-size companies collaborate with small high-tech enterprises and start-ups on regional/national/European-funded research projects. MESAP facilitates the knowledge transfer by organising workshops at the completion of each research project in order to disseminate results, or 'technology days', i.e., events with educational purposes, specifically aimed at explaining new technologies to MESAP members. Piedmont's business community expresses great satisfaction with the services provided by MESAP. At present, MEDIS is looking at MESAP as a model to understand the way how even smaller enterprises could be involved in the knowledge 
generation and diffusion process. Considering the differences between Apulia and Piedmont's industrial fabric, in particular the much more limited innovation capacity of Apulian small companies, MEDIS considers more appropriate to maintain its membership limited to the few most innovative medium and large enterprises. These will be in charge of producing new transferable knowledge. In parallel, following MESAP's example, MEDIS will identify a group of small and less innovative companies which will not be directly involved in research projects, but will benefit from technological transfer, absorbing, rather than directly producing, new knowledge.

The increase of mechanisms for knowledge transfer to local SMEs, the strengthening of ARTI's monitoring and evaluation capacity, along with the continuation of financial support provided by PugliaSviluppo and further development of human capital, are possibly the key means to improve the effectiveness of the RIS in Apulia. Until now, however, it is not entirely clear if the current experience will stabilise and eventually help to close the gap with the Piedmont benchmark.

\section{Conclusions}

This paper has provided some new insights that help to understand why and how RIS have managed to grow in disadvantaged areas. Based on the review of the existing literature, we have first built a conceptual framework that identifies the conditions that should be met for a RIS to emerge in a disadvantaged area. We have defined the ingredients at the base of a RIS and the actions that need to be taken to favour the emergence of a RIS. Notably, we argue that the creation of a RIS is the result of a dynamic multistep process initially promoted by public institutions through top-down logic, and then integrated by action of local actors through a bottom-up approach.

Given this framework, the paper moved to analyse the Apulian mechatronic cluster, named MEDIS, and the Apulian RIS with a historical perspective aimed at tracking the development of a regional industrial district and the evolution of the supporting policies over an extended period of time. The conceptual framework has represented a useful guideline to develop a critical analysis of the MEDIS structure and results, and to understand its strengths and weaknesses. We have found that the establishment of the MEDIS is the result of a long path that has been initially driven by the government action. The role of public institutions, their level of governance, their strategy and instruments has evolved over time to support the development of a frontier technological cluster in a lagging-behind region. A first direct intervention of the central government aimed at attracting major players in less developed areas has been progressively substituted towards a more indirect and strategic action of regional public institutions towards R\&D activities among interacting actors. The establishment of the MEDIS has been favoured by a well-functioning and structured local administrative machine which managed to increasingly address structural funds towards research and innovative activities and that acted to create an active network of various actors which operate in the field of mechanic and electric engineering.

We believe that this paper has brought some interesting contributions to the existing literature on RIS, and in particular on the evolution of the strategies, type of intervention and instruments that policy makers can adopt in developing innovation systems within regions. Our paper has been motivated by the observation that regions follow developing paths which usually differ among leading and follower areas, and that no universal 
recipes exist to support the establishment of a RIS. The type of government intervention, level of institutional governance and the adopted policy instruments should evolve in relation to the underlying socio-economic conditions and should vary along the different stages of development of an innovation system within a region. This points to the relevance of both the type of policies to be implemented and the timing for their implementation. These arguments brought the European Union to increasingly adopt a 'smart specialisation strategy'. This approach admits the possibility for any region to generate innovation, by leveraging its own strengths and competitive advantages and selectively targeting its place-based research and innovation strategy on those economic activities in which the region can hope to excel. However, the conditions which could actually ensure a synergic relation between different policies aiming at enhancing European competitiveness, overcoming possible obstacles and tensions, still have to be explored.

Even if drawn from one single case study, the analysis of the Apulian RIS highlights some policy recommendations and conditions for a place-based research and innovation policy that are sufficiently general to be of interest for other less developed EU regions. We recall them:

- As a first lesson, the Apulia case study highlights that innovation cannot occur in the middle of nowhere. Strong industrial vocation in a certain sector and an already well-established productive system, often developed in connection to a few large enterprises, are preconditions for a successful technological cluster to develop. The territory should also be endowed with universities producing skilled human capital and an adequate level of applied research, both of which could then be suitably employed to satisfy industrial technological needs. These ingredients are rather a pre-condition than part of the place-based innovation policy, as it takes often decades to establish an industrial fabric and a fairly good academic tradition in any region. Thus, selectivity is needed in establishing an ambitious place-based innovation strategy. Not all contexts are suitable, and a careful opportunity study should identify the appropriate places where to experiment such strategies.

- The regional or local government should define a clear, comprehensive and long-term development strategy focused on innovation. The importance of innovation for socio-economic development and convergence should be explicitly recognised, stated in policy papers, and pursued at all levels of government. This implies coordination of different agendas and departments. For example, measures in support of industrial technological advancement should be accompanied by a simultaneous effort to sustain human capital, able to generating technological change and exploiting the potentialities of the already existing comparative advantages. Political stability and continuity are crucial to guarantee such a long-term commitment and to ensure a smooth implementation of the strategy. This condition, in the last around ten years, was apparent in the Apulia case study.

- Besides a widespread policy vision about the role of innovation within government, there must be a well-functioning and structured administrative machine. The place-based dimension of innovation can be more effectively dealt by authorities operating at the regional or local level, which may have better knowledge of the characteristics and potentialities of the local research and industrial sectors. Regional governments can be more effective than national governments in detecting the needs 
arising bottom-up and in involving and coordinating the relevant stakeholders. The national government should sustain the RIS, by retaining some power of coordination and stimulus over research and innovation policies, but also by contributing to finance innovation and attract foreign direct investments in relatively less developed regions. The division of roles between the decision-making process, performed by national and regional authorities, and the execution tasks, performed by intermediate innovation agencies, would ensure a better exploitation of comparative advantages of different layers of government. Knowledge of the local context and more responsiveness to changing needs is typically place-based, while the overall funding strategy for long-term research and innovation is better managed by high-profile national bodies. Multilevel governance of the RIS can work well provided that all actors have clear and not overlapping mandate, commitment and enough financial and technical resources to carry out their tasks. The Apulia casehistory shows that the combination of national programs and regional policies were synergic in attracting and retaining large innovative firms, but also that occasionally there were difficulties in coordination between the national and the regional government.

- A sufficient volume of financial resources should be available to ensure the implementation of a minimum efficient scale of investments in research, industrial innovation, education and training. The combination of regional, national and European financing can help attain a critical mass to trigger a change in the development and innovation pattern. The significant volume of public contribution helps to reduce sunk costs of research and innovation, thus also favouring the attraction of extra-regional and multinational enterprises within the RIS. This happened in Apulia occasionally since the 1960s, and particularly with the 'programme agreements' in the 1990s and it shows the long-term resilience of such policy when the context is adequate (Giunta and Mantuano, 2010).

- The set of financial support instruments should be sufficiently diversified, so as to include grants and various financial engineering instruments, but also tailored to the specific needs of different types of beneficiaries. In particular, SMEs' difficulties in accessing capital for risky investments should be properly addressed. Access to funds is facilitated by the availability of a regional intermediate agency for public financing support, which can establish a more direct relationship and provide more tailored support to potential beneficiaries than a centralised authority. Apulia region had had some good experience in this area, but not yet enough to fully match the needs of SMEs. Binding conditionality in providing research grants should be foreseen to enhance their spill over effects.

- The RIS should be open to other regions and countries, in order to favour the exchange of ideas and knowledge. This can be achieved through the establishment of collaboration relationships with partners outside the regional territory and it can have a twofold effect: on the one side, technological clusters open to receive and absorb the new knowledge generated elsewhere are less likely to incur the risk of a lock-in situation; on the other side, the exchange of research and innovation results with other territories can produce positive spill over effects to other regions. In Apulia it was a positive ingredient that some of the major players gave access to the more advanced research and technology context of Piedmont or Germany, and that local 
private research centres already had some contacts with foreign research institutes. Elsewhere the wider network should be built as part of the strategy.

- The RIS should promote mainly the development of key enabling technologies. Developing cross-cutting pre-competitive technologies, which in principle could be applied to a variety of sectors, favours the diversification of the industrial basis and maximises the utility of generated knowledge. The types of technologies on which focusing the research and innovation efforts should be driven by the local industrial tradition, and selected through a participatory approach. This happened in the case of the Apulian mechatronics cluster, thanks to the initial important facilitator role played by the regional agency ARTI.

- The existence of appropriate mechanisms of knowledge transfer from the most innovative to less innovative enterprises is crucial to guarantee the diffusion of technological advancements and ideas to a wider number of actors, besides those which actually produce new knowledge in the first place. This process can transform technological excellence, which is typically highly idiosyncratic, into a driver of wider territorial socio-economic development. The existence of a common industrial vocation (as from point 1 above) increases the firm's capacity to absorb knowledge and to give it a practical application. The Apulia case study shows some difficulties in establishing knowledge transfer from the core players to the local SMEs.

The case study presented in this paper suggests that in principle several ingredients should simultaneously occur to sustain an effective innovation policy decentralised at regional level. We guess that this combination of ingredients is not frequent in lagging-behind local contexts in the EU Member States. Any regional innovation strategy significantly lacking one of the core pre-conditions and ingredients we have identified is risky. Policy-makers should carefully study the opportunities and challenges arising from local contexts before embarking in ambitious place-based innovation strategies. The Apulia case history on mechatronics, despite some fairly good results, shows that ten years of efforts are not enough to achieve long-term success when some, but not all, ingredients are available. On a more positive vein, however, the case study also shows that a place-based innovation policy in lagging behind regions is feasible, and has a potential to pay a growth-dividend to its stakeholders.

\section{References}

Asheim, B.T. and Coenen, L. (2005) 'Knowledge bases and regional innovation systems: comparing Nordic clusters', Research Policy, Vol. 34, No. 8, pp.1173-1190.

Audretsch, D.B. and Feldman, M.P. (1996) 'Innovative clusters and the industry life cycle', Review of Industrial Organization, Vol. 11, No. 2, pp.253-273.

Bacchiocchi, E., Florio, M. and Giunta, A. (2012) 'Internationalisation and the agglomeration effect in the global value chain: the case of Italian automotive suppliers', Int. J. of Technological Learning, Innovation and Development, Vol. 5, No. 3, pp.267-290.

Baldwin, R.E. and Martin, P. (2004) 'Agglomeration and regional growth', in Henderson, V. and Thisse, J.F. (Eds.): Handbook of Regional and Urban Economics: Cities and Geography, Elsevier, Amsterdam.

Baptista, R. (2000) 'Do innovation diffuse faster within geographical clusters?', Int. J. Ind. Organ, Vol. 18, pp.515-535. 
Becattini, G., Bellandi, M. and De Propris, L. (2009) A Handbook of Industrial Districts, Edward Elgar, Cheltenham, UK; Northampton, MA, USA.

Bell, M. (2006) 'Time and technological learning in industrializing countries: how long does it take? How fast is it moving (if at all)?', International Journal of Technology Management, Vol. 36, Nos. 1-3, pp.25-42.

Bell, M. and Albu, M. (1999) 'Knowledge systems and technological dynamism in industrial clusters in developing countries', World Development, Vol. 27, No. 9, pp.1715-1734.

Bell, M. and Figueiredo, P.N. (2012) 'Innovation capability building and learning mechanisms in latecomer firms: recent empirical contributions and implications for research', Canadian Journal of Development Studies, Vol. 33, No. 1, pp.14-40.

Bergek, A., Jacobsson, S., Carlsson, B., Lindmark, S. and Rickne, A. (2008) 'Analyzing the functional dynamics of technological innovation systems: a scheme of analysis', Res. Policy, Vol. 37, No. 3, pp.407-407.

Bernardes, A. and Albuquerque, E. (2003) 'Cross-over, thresholds, and interactions between science and technology: lessons for less developed countries', Res Policy, Vol. 32, pp.865-885.

Breschi, S. and Malerba, F. (1997) 'Sectoral innovation systems: technological regimes, Schumpeterian dynamics and spatial boundaries', in Edquist, C. (Ed.): Systems of Innovation: Technologies, Institutions and Organizations, Pinter, London.

Buesa, M., Heijs, J. and Baumert, T. (2010) 'The determinants of regional innovation in Europe: a combined factorial and regression knowledge product function approach', Res. Policy, Vol. 39, No. 6, pp.722-735.

Castellani, D. and Zanfei, A. (2003) 'Technology gaps, absorptive capacity and the impact of inward investments on productivity of European firms', Econ. Innov. New Technol., Vol. 12, No. 6, pp.555-576.

Chen, K. and Guan, J. (2011) 'Mapping the functionality of China's regional innovation systems: a structural approach', China Econ. Rev., Vol. 22, No. 1, pp.11-27.

Cohen, W.M. and Levinthal, D.A. (1990) 'Absorptive capacity: a new perspective on learning and innovation', Administrative Science Quarterly, Vol. 35, No. 1, pp.128-152.

Coletti, M. and Di Maria, E. (2015) 'The rush for cluster initiatives: cluster organisation and management in central Europe', Int. J. of Entrepreneurship and Innovation Management, Vol. 19, Nos. 5/6, pp.327-342.

Cooke, P., Uranga, M.G. and Etxebarria, G. (1997) 'Regional innovation systems: institutional and organizational dimensions', Res Policy, Vol. 26, pp.475-491.

Dantas, E. and Bell, M. (2009) 'Latecomer firms and the emergence and development of knowledge networks: the case of Petrobras in Brazil', Research Policy, Vol. 38, No. 5, pp.829-844.

Delgado, M., Porter, M.E. and Stern, S. (2010) 'Clusters and entrepreneurship', J. Econ. Geogr., Vol. 10, No. 4, pp.495-518.

Dhewanto, W., Lantu, D.C., Herliana, S. and Permatasari, A. (2016) 'The obstacles for science technology parks in a developing country', Int. J. of Technological Learning, Innovation and Development, Vol. 8, No. 1, pp.4-19.

Di Tommaso, M., Paci, D., Rubini, L. and Schweitzer, S. (2006) 'Is distance dead? High-tech clusters, analysis and policy perspectives', in Pitelis, C., Sugden, R. and Wilson, J.R. (Eds.): Clusters and Globalisation, Edward Elgar, Cheltenam, UK; Northampton, USA.

Dutrenit, G. (2000) 'Learning and knowledge management in the firm', in Knowledge Accumulation to Strategic Capabilities, Edward Elgar, Cheltenham.

Ebbekink, M. and Lagendijk, A. (2013) 'What's next in researching cluster policy: place-based governance for effective cluster policy', European Planning Studies, Vol. 21, No. 5, pp.735-753.

Edquist, C. (1997) Systems of Innovation: Technologies, Institutions and Organizations, Pinter, London. 
Edquist, C. and Johnson, B. (1997) 'Institutions and organisations in systems of innovation', in Edquist, C. (Ed): Systems of Innovation: Technologies, Institutions and Organisations, London and Washington, DC.

Etzkowitz, H. and Leydesdorff, L. (1996) 'A triple helix of academic-industry-government', Current Science, Vol. 70, pp.690-693.

European Commission (2012) Guide to Research and Innovation Strategies for Smart Specialisation (RIS 3), DG Regional Policy.

Eurostat (2013) Science, Technology and Innovation in Europe - 2013 Edition, Eurostat Pocketbooks.

Fagerberg, J. (2004) 'Innovation: a guide to the literature', in Fagerberg, J., Mowery, D. and Nelson, R. (Eds.): The Oxford Handbook of Innovation, pp.291-31, Oxford University Press, Oxford.

Fagerberg, J., Srholec, M. and Verspagen, B. (2010) 'Innovation and economic development', in Bronwyn, H.H. and Rosenberg, N. (Eds.): Handbook of the Economics of Innovation, Vol. 2, pp.833-872, North-Holland Publishing Company, Amsterdam.

Fernández-Sastre, J. and Martín-Mayoral, F. (2017) 'Assessing the impact of public support for innovation in an emerging innovation system', Int. J. of Technological Learning, Innovation and Development, Vol. 9, No. 1, pp.42-64.

Ferretti, M. and Parmentola, A. (2015) 'The creation of local innovation systems in emerging countries', in The Role of Governments, Firms and Universities, Springer Briefs in Regional Science, Springer.

Figueiredo, P.N. (2003) 'Learning, capability accumulation and firms differences: evidence from latecomer steel', Industrial and Corporate Change, Vol. 12, No. 3, pp.607-643.

Foray, D. and Van Ark, B. (2007) 'Smart specialisation in a truly integrated research area is the key to attracting more R\&D to Europe', Knowledge Economists Policy Brief, No. 1, October.

Foray, D., David, P.A. and Hall, B. (2009) 'Smart specialisation - the concept', Knowledge Economists Policy Brief, No. 9, June.

Fosfuri, A., Motta, M. and Ronde, T. (2001) 'Foreign direct investment and spill over through workers mobility', J. Int. Econ., Vol. 53, No. 1, pp.205-222.

Fritsch, M. and Stephan, A. (2005) 'Regionalization of innovation policy - introduction to the special issue', Research Policy, Vol. 34, No. 8, pp.1123-1127.

Gertler, M.S. (2003) 'Tacit knowledge and the economic geography of context, or the undefinable tacitness of being (there)', Journal of Economic Geography, Vol. 3, No. 1, pp.75-99.

Gilbert, B.A., Audretsch, D.B. and McDougall, P.P. (2004) 'The emergence of entrepreneurship policy', Small Business Economics, Vol. 22, Nos. 3-4, pp.313-323.

Giuliani, E. and Bell, M. (2005) 'The micro-determinants of meso-level learning and innovation: evidence from a Chilean wine cluster', Research Policy, Vol. 34, No. 1, pp.47-68.

Giunta, A. and Mantuano, M. (2010) 'Contratti di programma: evoluzione della normativa ed efficacia economica', Economia e Politica Industriale, No. 1.

Guimon, J. (2017) 'Policies to promote science-industry links and technology commercialisation in emerging countries: the case of Kazakhstan's Technology Commercialization Project', Int. J. of Technological Learning, Innovation and Development, Vol. 9, No. 1, pp.1-16.

Hospers, G-J. and Beugelskijk, S. (2002) 'Regional cluster policies: learning by comparing?', KYKLOS, Vol. 55, No. 3, pp.381-402.

Huggins, R. and Kitagawa, F. (2011) 'Regional policy and university knowledge transfer: perspectives from devolved regions in the UK', Reg. Stud., Vol. 46, No. 6, pp.817-832.

Iansiti, M. and Clark, K. (1994) 'Integration and dynamic capability: evidence from product development in automobiles and mainframe computers', Industrial and Corporate Change, Vol. 3, No. 3, pp.557-605.

Invitalia (2012) II Mezzogiorno Tecnologico, Una Ricognizione in sei Distretti Produttivi, prepared by Domenico Cersosimo and Gianfranco Viesti. 
Jacobsson, S. and Bergek, A. (2012) 'Innovation system analyses and sustainability transitions: contributions and suggestions for research', Survey. Environ. Innov. Societal Tran., Vol. 1, No. 1, pp.41-57.

Kallio, A., Harmaakorpi, V. and Pihkala, T. (2010) 'Absorptive capacity and social capital in regional innovation systems: the case of the Lahti region in Finland', Urban Stud., Vol. 47, No. 2, pp.303-319.

Katz, J. (1987) Technology Generation in Latin American Manufacturing Industries, Macmillan, London.

Keeble, D. and Wilkinson, F. (1999) 'Collective learning and knowledge development in the evolution of regional clusters of high technology SMEs in Europe', Regional Studies, Vol. 33, No. 4, pp.295-303.

Kim, L. (1998) 'Crisis construction and organisational learning: capability building in catching-up at Hyundai Motor', Organization Science, Vol. 9, No. 4, pp.506-521.

Krugman, P. (1991) 'Increasing returns and economic geography', Journal of Political Economy, Vol. 99, No. 3, pp.483-99.

Lau, A.K. and Lo, W. (2015) 'Regional innovation system, absorptive capacity and innovation performance: an empirical study', Technological Forecasting and Social Change, Vol. 92, pp.99-114.

Lehto, E. (2007) 'Regional impact of research and development on productivity', Regional Studies, Vol. 41, No. 5, pp.623-638.

Lewin, A.Y., Massini, S. and Peeters, C. (2011) 'Microfoundations of internal and external absorptive capacity routines', Organ. Sci., Vol. 22, No. 1, pp.81-98.

Lundvall, B.A., Joseph, K.J., Chaminade, C. and Vang, J. (2009) Handbook of Innovation System and Developing Countries. Building Domestic Capabilities in a Global Setting, Edward Elgar Publishing Ltd., Cheltenham UK and Northampton USA.

Lundvall, B-A. (1992) National Systems of Innovation towards a Theory of Innovation and Interactive, Learning, London.

Marcelle, G. (2004) Technological Learning: A Strategic Imperative for Firms in the Developing World, Edward Elgar, Cheltenham.

Markard, J. and Truffer, B. (2008) 'Technological innovation systems and the multi-level perspective: towards an integrated framework', Res. Policy, Vol. 37, No. 4, pp.596-661.

Martin, R. and Simmie, J. (2008) 'Path dependence and local innovation systems in city-regions', Innov.: Manage Policy Pract., Vol. 10, Nos. 2/3, pp.183-196.

Maskell, P. and Malmberg, A. (1999) 'The competitiveness of firms and regions: 'ubiquitification' and the importance of localized learning', European Urban and Regional Studies, Vol. 6, No. 1, pp.9-25.

Morrison, A., Pietrobelli, C. and Rabellotti, R. (2008) 'Global value chains and technological capabilities: a framework to study industrial innovation in developing countries', Oxf. Dev. Stud., Vol. 36, No. 1, pp.39-58.

Musiolik, J., Markard, J. and Hekkert, M. (2012) 'Networks and network resources in technological innovation systems: towards a conceptual framework for system building', Technol. Forecast. Soc. Chang., Vol. 79, No. 6, pp.1032-1048.

Nelson, R. (1993) National Innovation Systems: A Comparative Analysis, Oxford Univ. Press, New York.

OECD (2010) The OECD Innovation Strategy: Getting a Head Start on Tomorrow, Paris.

Parilli, M.D. (2009) 'Collective efficiency, policy inducement and social embeddedness: drivers for the development of industrial districts', Entrepreneurship Reg. Dev., Vol. 21, No. 1, pp.1-24.

Porter, M. (1998) 'Clusters and the new economics of competition', Harvard Business Review, Vol. 76, No. 6, pp.77-91.

Saxenian, A. (1994) Regional advantage: Culture and competition in Silicon Valley and Route 128, Harvard University Press, Cambridge, MA. 
Wolfe, D.A. and Gertler, M.S. (2006) 'Local antecedents and trigger events: policy implications of path dependence for cluster formation', in Braunerhjelm, P. and Feldman, M. (Eds.): Cluster Genesis, Technology-Based Industrial Development, pp.243-263, University Press, Oxford.

Yin, R. (2003) Case Study Research: Designs and Methods, 3rd ed., Sage Publications, Thousand Oaks, London.

Zanello, G., Fu, X., Mohnen, P. and Ventresca, M. (2015) 'The creation and diffusion of innovation in developing countries: a systematic literature review', Journal of Economic Surveys, Vol. 30, No. 5, pp.884-912.

\section{Notes}

1 Mechatronics is a technological intensive branch of engineering originally emerged from the application of electronics engineering to mechanical systems. Nowadays, mechatronics includes and combines new technical areas and several subfields of engineering such as electronic, control, computer and telecommunication. Mechatronics is fasting becoming a fundamental element in the new model of development in the high added-value industry. Given its multidisciplinary approach, it is increasingly finding new applications in several industries, such as aerospace, biomedical, material processing or defense systems. Notably, it is becoming the basis of the world's two largest in medium and high technology markets, namely the automotive and production systems, where tens of billions of Euro are annually invested all over the world.

2 Hereby we report the affiliation and position of the interviewed stakeholders: Director of the Regional Government of Apulia's Directorate 'Economic development, employment and innovation policies - industrial research and innovation'; President of ARTI - Regional Agency for Technology and Innovation; General Director of Puglia Sviluppo S.p.A.; President of MEDIS, Apulian Mechatronics Technological Cluster; Professor of Experimental Physics at the University of Bari; CEO of the Bosch private research centre 'Centro Studi Componenti Per Veicoli S.p.A.'; CEO of MASMEC S.p.A.; CEO of Fiat Research Centre; Technology manager of MESAP - Piedmont's Cluster of Mechatronics and Advanced Production Systems; Professor of Economics at the University of Bari; Director of Confindustria Puglia (Business Representative Association of Apulia).

3 This is still the second biggest Italian plant of the Swedish multinational company which builds machinery components for the automotive industry and currently employs 292 workers in Bari (data refers to 2015).

4 In the early 90's, the Bari CRF developed the Common Rail technology, a new injection system for diesel-powered engines, to which about 50 patents are associated and which is nowadays widely adopted in the automotive vehicles. Lacking internal capacity and financial resources to bring the technology onto the market, Fiat sold to Bosch the license to industrialize the common rail system. Bosch invested substantial resources both in the production and in the research activities.

5 Regulated by Law 267/2000, these contracts grant incentives to large enterprises to contribute to the recovery and the consolidation of existing industries and the creation of new development opportunities, strengthening the competitiveness and attractiveness of the region and supporting employment. In particular, for the realization of a 187 million Euros investment, Getrag received a 98.6 million EUR fund provided by the central government and 19 million euro granted by the Puglia region.

6 The ICT of the Aquila (Abruzzo), the aerospace system of Campania, the system of mechatronics in Apulia, the Apulian Air Force system and the Cagliari ICT system (Sardinia).

7 MEDIS Stakeholders are as follows: private members (Confindustria Bari $8.9 \%$, FIAT Reasearch Centre 4.9\%, Magneti Marelli Powertrain 4.9\%, Centro Studi Componenti per Veicoli - Bosch 4.9\%), Getrag 4.9\%, Itel 5.24\%, Mermec 5.24\%, Masmec 5.24\%, Laser centre $0.9 \%$, Sintesi $3.88 \%$ ) and public members (University of Bari $25.5 \%$, Polytechnic University of Bari $20.5 \%$, University of Salento $5 \%$ ). 
8 Including, among others, various CNR institutes, the European and Italian platforms MANUFACTURE, Fraunhofer Institute of Jena, Instituto de Desenvolvimento de Novas Tecnologia of Lisbon, Royal Institute of Technology of Stockholm, Institute for Production of Cologne Fachhoschscule, and several Italian and European universities.

9 The main project related to the second intervention area of MEDIS, 'Development of innovative mechatronic security systems (wired and wireless) for railway, aerospace and robotic applications', is involving other nine regional companies, three Italian companies, the Apulian productive Mechanics cluster, the Apulian Aerospatial Productive and Technological clusters, the European association of Railway companies (UIC) and the European Association of railway system manufacturers (UNIFE).

10 An example is Icam S.r.l., which designs and manufactures intelligent automatic storage and filing systems, allowing efficiently exploiting available space and better organising the working environment. In 2007 when MEDIS was set up, Icam was too small and did not have enough capacity to produce research, but over the past years it has significantly grown.

11 MESAP is not defined as a technological cluster strictu sensu, but it is an independent association managed by Unione Industriale, the Turin business representative association. 